\title{
Pacific Mean-State Control of Atlantic Multidecadal Oscillation-El Niño Relationship
}

\author{
DONGMIN KIM \\ Cooperative Institute for Marine and Atmospheric Studies, University of Miami, and NOAA/Atlantic Oceanographic and \\ Meteorological Laboratory, Miami, Florida \\ SANG-Ki LEE AND HOSMAY LOPEZ \\ NOAA/Atlantic Oceanographic and Meteorological Laboratory, Miami, Florida \\ MARLOS GOES \\ Cooperative Institute for Marine and Atmospheric Studies, University of Miami, and NOAA/Atlantic Oceanographic and \\ Meteorological Laboratory, Miami, Florida
}

(Manuscript received 30 May 2019, in final form 6 December 2019)

\begin{abstract}
We investigate the potential impacts of the interdecadal Pacific oscillation (IPO) and Atlantic multidecadal oscillation (AMO) on El Niño and the associated atmosphere and ocean dynamics by using the Community Earth System Model-Large Ensemble Simulation (CESM-LENS). The individual effects of IPO and AMO on El Niño frequency and the underlying atmosphere-ocean processes are well reproduced in CESM-LENS and agree with previous studies. However, the sensitivity of El Niño frequency to the AMO is robust mainly during the negative IPO phase and very weak during the positive IPO phase. Further analysis suggests that the atmospheric mean state in the Pacific is much amplified during the negative IPO phase, facilitating the AMOinduced interocean atmospheric teleconnections. More specifically, during the negative IPO phase of the amplified mean state, the positive AMO enhances ascending motion from the northeastern Pacific, which in turn increases subsidence into the southeast Pacific through local anomalous Hadley circulation. The associated low-level easterly wind anomalies in the central equatorial Pacific are also reinforced by amplified upper-level divergence over the Maritime Continent to enhance the negative IPO, which is unfavorable for El Niño occurrence. Conversely, the negative AMO nearly cancels out the suppressing effect of the negative IPO on El Niño occurrence. During the positive IPO phase of the weakened atmospheric mean state, however, the AMO-induced interocean atmospheric teleconnections are much weaker; thus, neither the positive nor the negative AMO has any significant impact on El Niño occurrence.
\end{abstract}

\section{Introduction}

El Niño is a fully coupled atmosphere-ocean process characterized by highly positive and persistent sea surface temperature anomalies (SSTAs) in the equatorial Pacific. El Niño induces significant climate variability and affects severe weather events over various parts of the globe via the direct forcing and atmospheric teleconnection, and thus it is considered the most significant climate phenomenon at the interannual time scale. For instance, El Niño is known to directly influence the formation of tropical cyclones over the western North Pacific (Camargo and Sobel 2005;

Corresponding author: Dr. Dongmin Kim, dongmin.kim@noaa.gov
Camargo et al. 2007; Li and Zhou 2012; Kim et al. 2013; $\mathrm{Wu}$ et al. 2014, 2018) and the interannual variation of the East Asian monsoon (Wang and Fan 1999; Wu et al. 2003; Zhou and Chan 2007; Feng et al. 2011). It also modulates the variability of winter precipitation over North America (e.g., Lee et al. 2014; Hoell et al. 2016; Jong et al. 2016; Lee et al. 2018; Lopez and Kirtman 2018) through extratropical stationary Rossby wave trains.

Previous studies have shown that multidecadal SST variations in the Pacific and Atlantic Oceans modulate the frequency of El Niño and thus the remote influence of El Niño on the global hydrological cycle (Power et al. 1999; Henley et al. 2013; Chen et al. 2013; Khedun et al. 2014; Westra et al. 2015). The dominant 
mode of the low-frequency Pacific SST variability is the Pacific decadal oscillation (PDO), which is defined as the principal component of North Pacific SSTAs poleward of $20^{\circ} \mathrm{N}$ (Mantua et al. 1997; Newman et al. 2016). The spatial pattern of the PDO is very similar to that of the interdecadal Pacific oscillation (IPO), which is defined as the low-pass-filtered SSTAs' difference between the tropical Pacific and the northwestsouthwest Pacific (Power et al. 1999; Henley et al. 2015). These decadal variations in the Pacific oscillate between a warm and a cold phase every 20-30 years (e.g., Newman et al. 2016). The time series of the PDO and IPO are also highly correlated; thus, the PDO and IPO are often used interchangeably in the literature (Folland et al. 2002; Verdon and Franks 2007). We use the IPO in this study since it represents the basinwide SST variability for the entire Pacific while the PDO represents only the North Pacific SSTAs' variability. It is well established that El Niño tends to occur more frequently and persist longer during the positive IPO/PDO phase and vice versa during the negative IPO/PDO phase (Kiem et al. 2003; Verdon and Franks 2007; Feng et al. 2014; Lin et al. 2018). This is because during the positive phase of IPO/PDO, the warm SSTAs in the eastern equatorial Pacific and the associated westerly wind anomalies along the equatorial Pacific provide favorable environments for El Niño occurrence (Wu et al. 2003; Wang et al. 2008; Feng et al. 2014).

A number of studies have suggested that the frequency of El Niño is affected by not only the Pacific SSTAs but also the North Atlantic SSTAs. In particular, it has been shown that the Atlantic multidecadal oscillation (AMO), which is defined as the detrended low-frequency SSTAs averaged over the North Atlantic (e.g., Enfield et al. 2001), could affect El Niño occurrence (Dong et al. 2006; Dong and Sutton 2007; Timmermann et al. 2007; Sung et al. 2015; Levine et al. 2017). Previous studies have shown that the cold SSTAs in the North Atlantic (i.e., negative AMO phase) and the associated anomalous subsidence in the North Atlantic produce anomalous ascending motion over the North Pacific, which in turn produces westerly wind anomalies in the tropical Pacific and thus leads to a favorable condition for El Niño occurrence (Dong et al. 2006; Sung et al. 2015). The AMOinduced tropical Pacific wind anomalies further modulate the Pacific Walker circulation via the zonal variation of SST and deep tropical convection along the equatorial Pacific (Levine et al. 2018). Consistent with this AMOinduced interocean teleconnection, several recent studies have shown that warm SSTAs in the tropical North Atlantic tend to decrease the frequency of El Niño events and increase the frequency of La Niña events (Ham et al. 2013; Cai et al. 2019; Park et al. 2019).
As briefly summarized above, numerous studies have investigated the modulating impacts of IPO/PDO and AMO on El Niño occurrence. However, as shown in Fig. 1a, there was rarely an extended decadal period during which the IPO signal dominates while the AMO is a neutral phase or the AMO signal dominates over a neutral IPO phase. Therefore, in order to better understand the low-frequency modulation of El Niño frequency, it is important to explore the interactive influence of the IPO and AMO on El Niño activity, which has never been attempted before this study. For example, Figs. 1b-e show the observed El Niño frequency under the four interactive IPO-AMO phases, namely, $(+)$ IPO and (-) AMO, (+) IPO and (+) AMO, (-) IPO and (-) AMO, and ( - ) IPO and $(+)$ AMO over 148 years (1870-2017) derived from the Extended Reconstructed SST, version 5 (ERSST5; Huang et al. 2017). During the positive IPO phases, the impacts of AMO on El Niño occurrence are insignificant. However, during the negative IPO phases, the AMO strongly affects El Niño frequency (i.e., less frequent during the positive AMO phases and more frequent during the negative AMO phases). These results suggest that the impacts of AMO on El Niño frequency depend critically on the IPO phase.

The overarching goal of this study is to understand the interactive influence of the IPO and AMO on El Niño frequency and the associated atmosphere-ocean processes. Since the observational records during the instrumental period are not long enough to establish statistically significant results, we analyze the preindustrial model runs based on the Community Earth System Model-Large Ensemble Simulation (CESM-LENS; Kay et al. 2015) and CESM-Atmospheric General Circulation Model (AGCM) experiments. We first examine the changes in El Niño frequency and the associated atmosphere-ocean dynamics during different phases of the IPO and AMO individually. Then, we perform composite analyses for four interactive IPO-AMO phases. The composite analyses reveal that the modulating impact of AMO on El Niño is robust mainly during the negative IPO phase, and it is very weak during the positive IPO phase. Therefore, we further propose and test a hypothesis to explain the strong asymmetry in the AMO-El Niño relationship with respect to the IPO phase, highlighting the importance of the eastern Pacific mean state on the AMO-induced interocean atmospheric teleconnections.

\section{Data and model simulation}

We use the European Centre for Medium-Range Weather Forecasts twentieth-century reanalysis (ERA20; Poli et al. 2016) to analyze the upper- and low-level (200 and $850 \mathrm{hPa}$, respectively) atmospheric circulation 

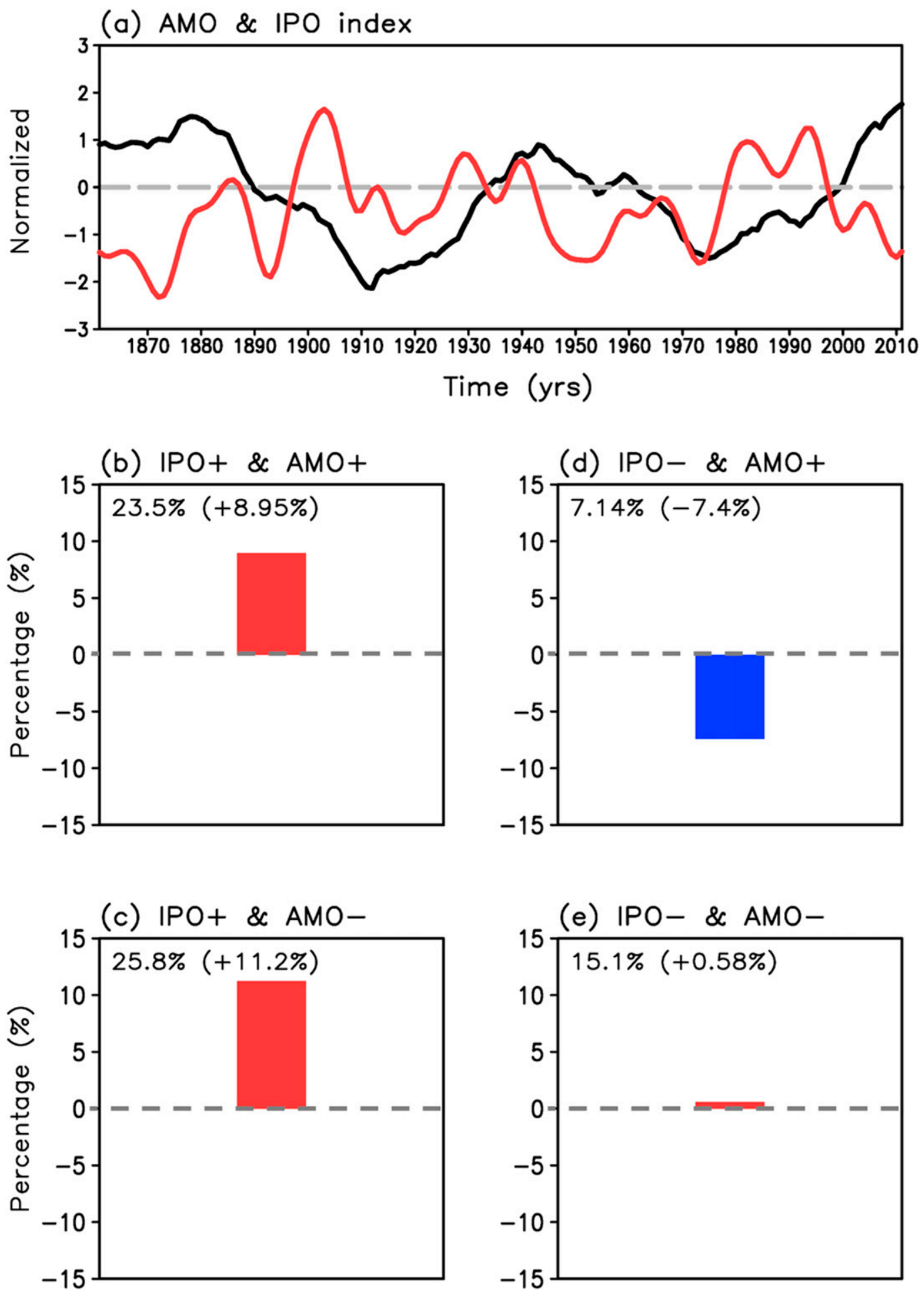

FIG. 1. (a) The time series of the normalized AMO (black line) and IPO (red line) taken from Kaplan SST and ERSST5, respectively. The percentages of observed El Niño occurrence (b) during the positive IPO and AMO [i.e., (+) IPO and (+) AMO], (c) during the positive IPO and negative AMO [i.e., (+) IPO and (-) AMO], (d) during the negative IPO and positive AMO [i.e., (-) IPO and (+) AMO], and (e) during the negative IPO and AMO [i.e., (-) IPO and (-) AMO] for 148 years (1870-2017). The numbers in parentheses are the anomalous percentage of El Niño occurrence from climatology. The climatological mean percentage of observed El Niño occurrence is $14.5 \%$. 
anomalies, under different phases of the IPO and AMO during the instrumental period (1900-2010). The IPO and AMO indices for the same period are computed by using the ERSST5 and the Kaplan Extended SST, version 2 (Kaplan et al. 1998), respectively. The AMO index is computed by spatially averaging SSTAs over the North Atlantic $\left(0^{\circ}-60^{\circ} \mathrm{N}, 70^{\circ} \mathrm{W}-0^{\circ}\right)$ following Enfield et al. (2001). The IPO index is calculated as the SSTAs' difference between the central equatorial Pacific $\left(10^{\circ} \mathrm{S}-10^{\circ} \mathrm{N}\right.$, $\left.170^{\circ} \mathrm{E}-90^{\circ} \mathrm{W}\right)$ and the northwest $\left(25^{\circ}-45^{\circ} \mathrm{N}, 140^{\circ} \mathrm{E}-145^{\circ} \mathrm{W}\right)$ and southwest Pacific $\left(50^{\circ}-15^{\circ} \mathrm{S}, 150^{\circ} \mathrm{E}-160^{\circ} \mathrm{W}\right)$ following Henley et al. (2015). The positive IPO phase indicates that SSTAs in the equatorial Pacific are higher than those in the northwest and southwest Pacific, and vice versa for the negative IPO. To remove the impact of anthropogenic global warming, the IPO and AMO indices as well as the atmospheric circulation anomalies are linearly detrended. We then apply a 11-yr running average to the IPO and AMO indices to focus on decadal and longer time scales.

Since the observational records during the instrumental period are not long enough to establish statistically significant results, the preindustrial model run from CESM-LENS (Kay et al. 2015) is used as the main tool in this study. The CESM consists of the atmosphere, land, ocean, glaciers, and sea ice components that exchange momentum, moisture and heat fluxes. The atmospheric model is Community Atmospheric Model, version 5 (CAM5), with the finite-volume dynamical core. It has 30 hybrid vertical levels from the surface to $3 \mathrm{hPa}$ and the horizontal resolution of $1.25^{\circ}$ longitude $\times 0.94^{\circ}$ latitude. The ocean component is Parallel Ocean Program, version 2 (POP2; Danabasoglu et al. 2012). It has 60 vertical levels with roughly $1^{\circ}$ horizontal resolution. We evaluate 1100 model years of CESM-LENS under preindustrial constant $\mathrm{CO}_{2}$ level. More detailed model description and additional features of CESM-LENS can be found in Kay et al. (2015). The IPO and AMO indices from CESM-LENS are obtained using the same method used for the observation-based reconstruction data. As in the observation-based data, we apply a 11-yr running average for all model variables. However, since there is no anthropogenic forcing in the preindustrial run, it is not necessary to remove the linear trend.

To test our working hypothesis for the impacts of four interactive IPO-AMO phases on the El Niño frequency, we perform the four AGCM experiments using CESM, version 1.2. The atmospheric model component of the CESM have 27 vertical levels with $1.9^{\circ} \times 2.5^{\circ}$ horizontal resolution. The Pacific and Atlantic SSTs prescribed in the four CESM-AGCM experiments are built by combining the climatological SSTs with SSTAs regressed on each of the four interactive IPO and AMO phases over 151 years (1861-2011) based on ERSST5 (similar to Figs. $2 \mathrm{c}$ and $2 \mathrm{~d})$. For example, in the (+) IPO and (-) AMO case, the Pacific Ocean between $40^{\circ} \mathrm{S}$ and $70^{\circ} \mathrm{N}$ is prescribed with the positive IPO SSTAs, while the Atlantic Ocean between $40^{\circ} \mathrm{S}$ and $70^{\circ} \mathrm{N}$ is prescribed with the negative AMO SSTAs. In the (+) IPO and $(+)$ AMO case, the Pacific Ocean between $40^{\circ} \mathrm{S}$ and $70^{\circ} \mathrm{N}$ is prescribed with the positive IPO SSTAs, while the Atlantic Ocean between $40^{\circ} \mathrm{S}$ and $70^{\circ} \mathrm{N}$ is prescribed with the positive AMO SSTAs. Note that the negative IPO SSTAs have the same amplitude as the positive IPO SSTAs with the opposite sign. Similarly, the negative AMO SSTAs have the same amplitude as the positive AMO SSTAs with the opposite sign. The four CESM-AGCM experiments are integrated for 30 years, and only the results from the last 10 years are used for analysis.

\section{Results}

\section{a. SSTAs and atmospheric circulation anomalies linked to the IPO and AMO in ERA20}

We first examine the key features of the observationbased IPO and AMO during the instrumental period. Figure 1a shows the time series of the AMO and IPO indices for 151 years (1861-2011) obtained from ERSST5. The correlation between the two indices is statistically insignificant $(r=-0.21)$, suggesting that the two modes are dynamically independent from one another (Park and Latif 2010).

Figures $2 \mathrm{a}$ and $2 \mathrm{~b}$ show the anomalous velocity potential and divergence wind fields at $200 \mathrm{hPa}$ partially regressed on the IPO and AMO indices, respectively, for 111 years (1900-2010). Figures $2 c$ and $2 d$ are the same as Figs. 2a and 2b, but for SST and wind fields at $850 \mathrm{hPa}$. The positive IPO, which is characterized by warm SSTAs over the central and eastern tropical Pacific, is matched by the anomalous upper-level divergence. Concurrently, anomalous upper-level convergence appears in the regions from the western Pacific warm pool to eastern Australia and to the northwest Pacific. The zonally contrasting pattern of anomalous upper-level velocity potential in the tropical Pacific (Fig. 2a) is consistent with the strong zonal SSTAs gradient (Fig. 2c).

As shown in Fig. 2b, the upper-level velocity potential and divergent winds regressed on the AMO are quite distinct from those on the IPO. The anomalous upperlevel convergence that appears over the central tropical Pacific is likely to be an integrated response to compensate for the anomalous upper-level divergence over the North Atlantic, where strong positive SSTAs occur 
(a) Partial reg coef. (IPO)

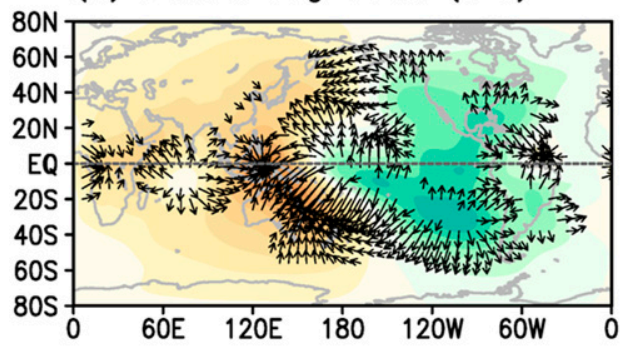

(c) Partial reg coef. (IPO)

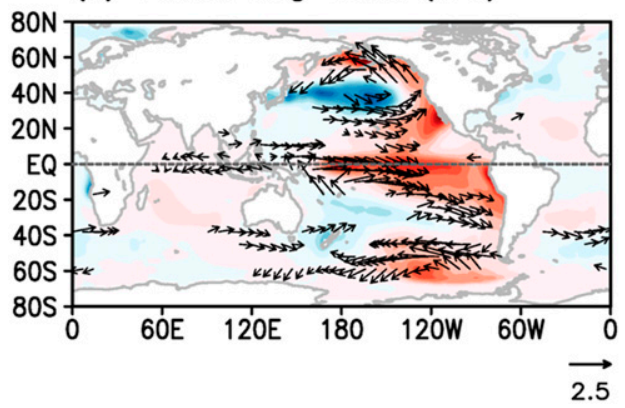

(b) Partial reg coef. (AMO)

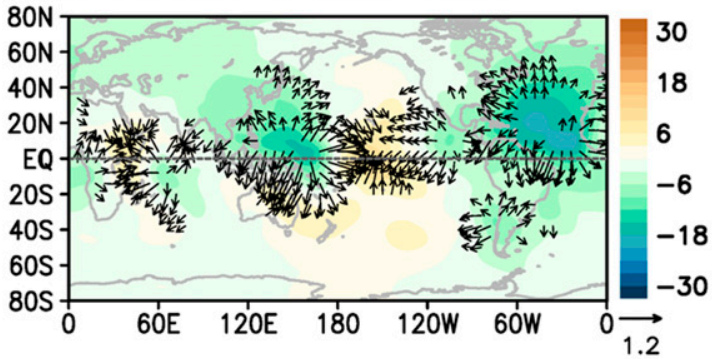

(d) Partial reg coef. (AMO)

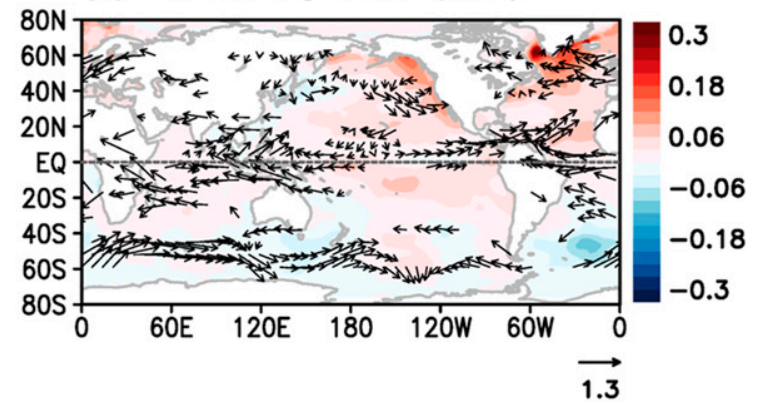

FIG. 2. Partial regression of velocity potential (shading, $10^{5} \mathrm{~m}^{2} \mathrm{~s}^{-1}$ ), and divergence winds at $200 \mathrm{hPa}$ (vectors, $\mathrm{m} \mathrm{s}^{-1}$, omitted below $0.3 \mathrm{~m} \mathrm{~s}^{-1}$ ) to (a) IPO and (b) AMO during 1900-2010 from ERA20. (c),(d) As in (a),(b), but for SST (shading, K) and winds at the $850 \mathrm{hPa}$ (vectors, $\mathrm{m} \mathrm{s}^{-1}$, omitted below $0.6 \mathrm{~m} \mathrm{~s}^{-1}$ ).

(Sun et al. 2017). A secondary anomalous upper-level divergence appears over the western Pacific warm pool, which involves rather complex atmosphereocean feedback processes in response to the central Pacific anomalous upper-level convergence (Sun et al. 2017; Zuo et al. 2018) and changes in low-level winds over the Indian Ocean ( $\mathrm{Li}$ et al. 2016; Cai et al. 2019).

\section{b. SSTAs and atmospheric circulation anomalies linked to the AMO and IPO in CESM-LENS}

In the previous section, we examine the upper- and low-level atmospheric circulations responses to the IPO and AMO, derived from ERA20. In this section, we investigate the characteristics of the IPO and AMO and the associated atmospheric circulation anomalies in CESM-LENS. The time series of the AMO and IPO for 1100 model years are shown in Fig. 3. The correlation between the AMO and IPO is about 0.11, which is statistically insignificant, in agreement with the observations. The positive and negative phases of the IPO and AMO are defined as the periods of a half standard deviation above and below the mean, respectively, as indicated by red and blue colors in Fig. 3. Note that the duration of IPO in CESM-LENS is comparable to that in the observation $(\sim 8$ years determined by the autocorrelation value at 0.2 ). However, the duration of AMO in CESM-LENS is shorter ( $\sim 10$ years) than that in the observation ( $\sim 14$ years). However, since this study focuses on the instantaneous interactions between IPO and AMO, it is unlikely that our results are strongly affected by this systematic bias in CESMLENS. Potential influences of this and other model biases on our results are discussed in the summary and discussion section.

Figure 4a shows the 200-hPa velocity potential and divergent winds partially regressed on the IPO. Figure $4 \mathrm{~b}$ is the same as Fig. 4a, but for the SSTAs and $850-\mathrm{hPa}$ wind anomalies. The anomalous upper-level divergence centered over the southeast Pacific and along the equatorial Pacific is consistent with the warm tropical Pacific SSTAs associated with the positive IPO phase. The anomalous upper-level divergence over the southeast Pacific and along the equatorial Pacific is balanced by the anomalous upper-level convergence centered over the Maritime Continent. As shown in Fig. 4b, during the positive IPO phase, low-level westerly wind anomalies prevail in the western tropical Pacific, which are consistent with the El Niño-like SSTAs in the tropical Pacific. The low-level westerly wind anomalies in the tropical Pacific are reinforced by a pair of persistent low-level cyclonic circulation anomalies that appear over the subtropical Pacific in both hemispheres. It should be noted that there are some discrepancies in the location of the IPO-induced anomalous upper-level 
(a) AMO index

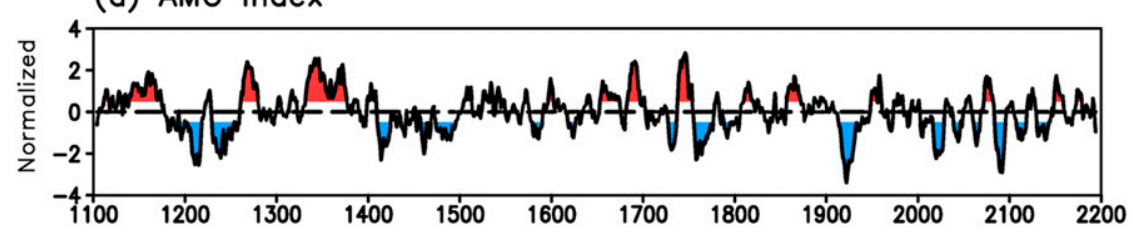

(b) IPO index

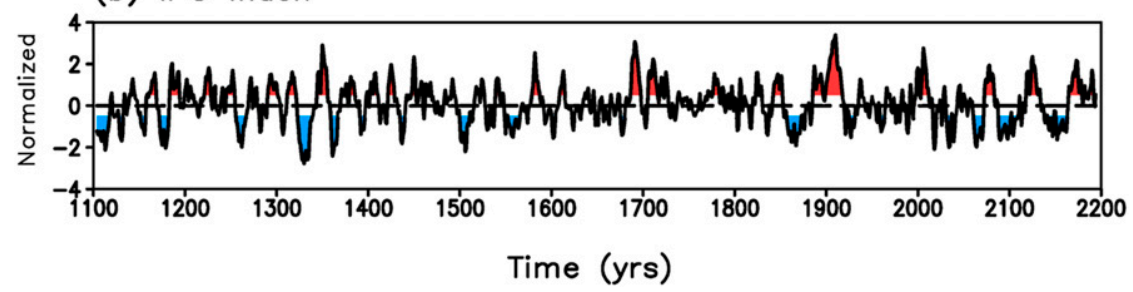

FIG. 3. The time series of the 11-yr running mean average of the normalized (a) AMO and (b) IPO indices for the CESM simulation during 1100 model years. The red (blue) filled color indicates the values of indices greater (less) than 0.5 standard deviation.

divergence fields between ERA20 and CESM-LENS. In particular, the upper-level convergence response over the Maritime Continent is slightly shifted westward to the eastern Indian Ocean in CESM-LENS. Despite this discrepancy between CESM-LENS and ERA20, the zonal contrast of anomalous upper-level divergence associated with the IPO is reasonably well reproduced in CESM-LENS.

Figure $4 \mathrm{c}$ shows the $200-\mathrm{hPa}$ velocity potential and divergent winds partially regressed on the AMO. Figure $4 d$ is the same as Fig. 4c, but for SSTAs and $850-\mathrm{hPa}$ wind anomalies. In response to the positive AMO phase, anomalous upper-level divergence appears over the North Atlantic and the northeastern Pacific $\left(0^{\circ}-15^{\circ} \mathrm{N}, 100^{\circ}-80^{\circ} \mathrm{W}\right)$. In response to the rising motion and anomalous upper-level divergence, strong anomalous upper-level convergence develops over the North Pacific $\left(0^{\circ}-50^{\circ} \mathrm{N}, 180^{\circ}-120^{\circ} \mathrm{W}\right)$ and weaker anomalous upper-level convergence over the southeast Pacific $\left(30^{\circ}-10^{\circ} \mathrm{S}, 100^{\circ}-80^{\circ} \mathrm{W}\right)$. Strong anomalous upper-level divergence also develops over the western Pacific $\left(10^{\circ} \mathrm{S}-30^{\circ} \mathrm{N}, 80^{\circ}-150^{\circ} \mathrm{E}\right)$, which is a secondary response associated with either the anomalous upper-level convergence over the North Pacific, suggested by Sun et al. (2017), or the Atlantic-to-Indian teleconnections suggested by Li et al. (2016).

As shown in Fig. 4d, during the positive AMO phase, low-level cyclonic circulation anomalies prevail over the tropical and subtropical North Atlantic, consistent with the warm SSTAs and the anomalous upper-level divergence. Consistent with the anomalous upper-level convergence and subsidence over the central North Pacific (Fig. 4c), anomalous low-level anticyclonic circulation develops over the tropical and subtropical North Pacific.
It appears that the associated equatorial Pacific lowlevel easterly wind anomalies reinforce the low-level convergence and upper-level divergence over the western Pacific, as suggested by previous studies (Dong et al. 2006; Li et al. 2016; Sun et al. 2017).

The direct and remote influences of the AMO on the atmospheric circulation in CESM-LENS are overall consistent with those derived from ERA20, and they also agree with previous studies (Zhang and Delworth 2005, 2007; Dong et al. 2006; Li et al. 2016; Levine et al. 2017; Sun et al. 2017). However, the exact locations of the anomalous upper-level divergence fields are somewhat different between ERA20 and CESM-LENS. For instance, the upper-level convergence in the central North Pacific is shifted northward in CESM-LENS compared to ERA20. The upper-level divergence centered over the western Pacific warm pool is slightly displaced toward the Maritime Continent in CESMLENS compared to ERA20. Despite these discrepancies, the zonal pattern of the anomalous upper-level divergence along the tropical Pacific, which is the key component in the AMO-El Niño relationship, agrees well between CESM-LENS and ERA20.

\section{c. Interactive influences of the IPO-AMO phases on El Niño occurrence}

Previous studies (e.g., Kiem et al. 2003; Dong et al. 2006; Feng et al. 2014; Sung et al. 2015) and the partial regression maps shown in Figs. 2 and 4 strongly suggest that El Niño occurrence could be modulated by a linear combination of the IPO and AMO phases. More specifically, it is expected that the frequency of El Niño would increase during the (+) IPO and (-) AMO phase and decrease during the (-) IPO and (+) AMO phase. 
(a) Partial reg coef. (IPO)

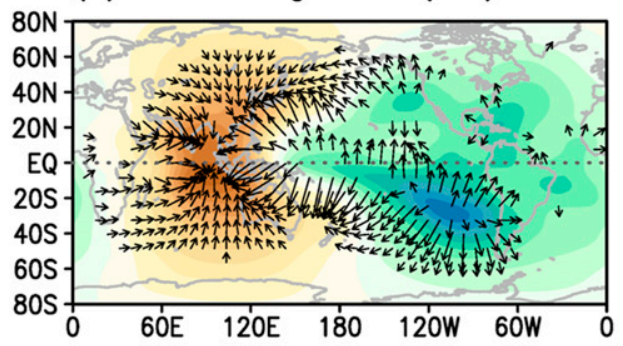

(b) Partial reg coef. (IPO)

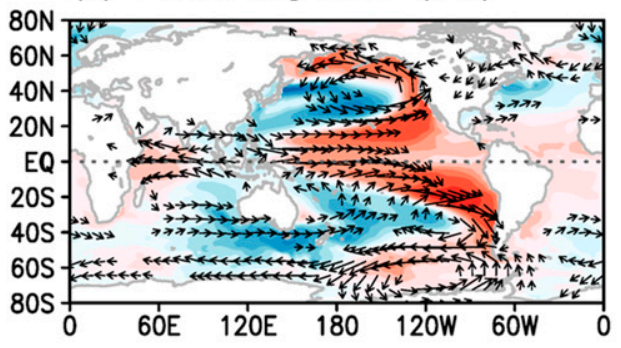

(c) Partial reg coef. (AMO)

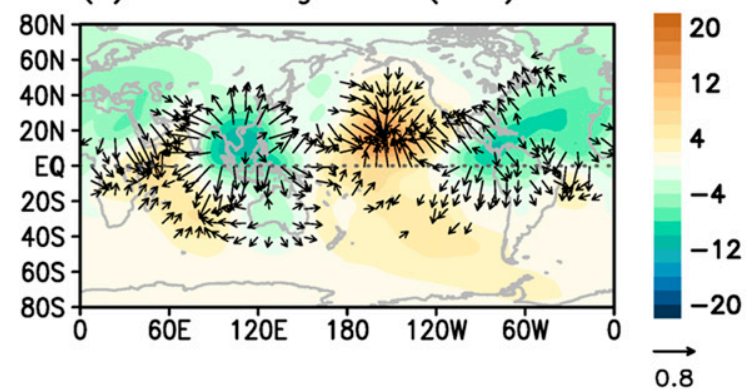

(d) Partial reg coef. (AMO)

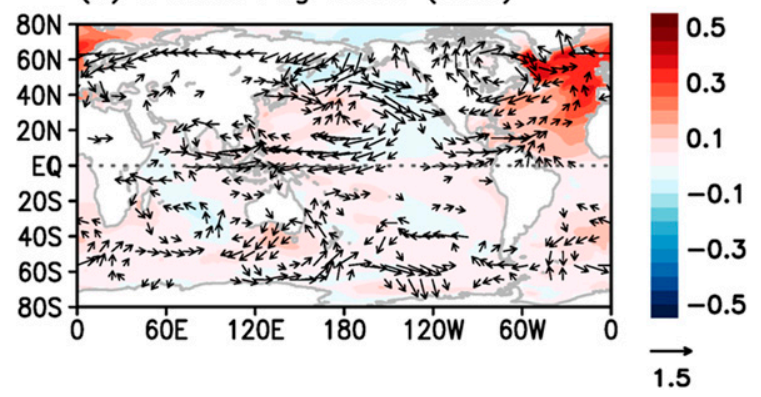

FIG. 4. Partial regression of simulated velocity potential (shading, $10^{5} \mathrm{~m}^{2} \mathrm{~s}^{-1}$ ) and divergence wind at $200 \mathrm{hPa}$ (vectors, $\mathrm{m} \mathrm{s}^{-1}$, omitted below $0.2 \mathrm{~m} \mathrm{~s}^{-1}$ ) onto (a) IPO and (b) AMO indices in 1100 model year from CESMLENS. (c),(d) As in (a),(b), but for SST (shading, K) and winds at $850 \mathrm{hPa}$ (vectors, $\mathrm{m} \mathrm{s}^{-1}$, omitted below $0.3 \mathrm{~m} \mathrm{~s}^{-1}$ ).

However, based on the observation, the changes in El Niño frequency with respect to the four interactive IPO-AMO phases is nonlinear, as shown in Figs. 1b-e. Although this observation-based result is statistically insignificant, it suggests a potential nonlinear interaction between IPO and AMO and its impact on El Niño frequency. Therefore, we explore in this section the changes in the frequency of El Niño under the four different interactive IPO-AMO phases using CESMLENS, similar to Figs. 1b-e.

Following the convention used by the Climate Prediction Center (CPC) of the National Oceanic and Atmospheric Administration, El Niño is defined when the 3-monthaveraged SSTAs in Niño-3.4 regions $\left(5^{\circ} \mathrm{S}-5^{\circ} \mathrm{N}, 150^{\circ}-\right.$ $90^{\circ} \mathrm{W}$ ) exceed $0.5^{\circ} \mathrm{C}$ for at least five consecutive months. A total of $263 \mathrm{El}$ Niño events are identified during the 1100 model years $(23.9 \%)$. These El Niño events are grouped into the four different combinations of the IPO and AMO phases. Figure 5 shows the percentages of El Niño occurrence, which is defined by the number of El Niño years divided by the total years, for each of the four interactive IPO-AMO phases. During the total 114 years of the (+) IPO and (+) AMO phases (Fig. 5a), 35 El Niño events occur $(30.7 \%)$. During the 89 years of the (-) IPO and (-) AMO phases (Fig. 5d), 21 El Niño events occur $(23.5 \%)$. The lowest percentage of El Niño occurrence $(11.4 \%)$ is found during the $(-)$ IPO and $(+)$
AMO phases (10 El Niño events during the total 87 years, Fig. 5c), while the highest percentage of El Niño occurrence $(33.3 \%)$ is found during the (+) IPO and (-) AMO phases (27 El Niño events during the total 81 years, Fig. 5b). All interactive IPO-AMO phases except for the (-) IPO and (-) AMO phases are significantly different from the climatology of El Niño occurrence. These suggest that the (+) IPO and (-) AMO phase provides the most favorable background condition for El Niño occurrence, while the (-) IPO and (+) AMO phase provides the least favorable condition, which is overall in line with previous studies (Kiem et al. 2003; Verdon and Franks 2007; Dong et al. 2006; Dong and Sutton 2007; Sung et al. 2015; Levine et al. 2017; Lin et al. 2018).

Interestingly, the modulating influence of AMO on El Niño occurrence, which can be measured by the difference in the percentage of El Niño occurrence between the positive and negative phase of AMO, is robust only during the negative IPO phase $[12.1 \%$ decrease from $(-)$ to $(+)$ AMO phase] and nearly negligible during the positive IPO phase $[2.6 \%$ decrease from $(-)$ to $(+)$ AMO, which is not significant at the $5 \%$ level]. This apparent asymmetric influence of the AMO on El Niño with respect to the IPO phase is consistent with the results from observations (Figs. 1b-e). This result has never been shown or discussed in the literature and 

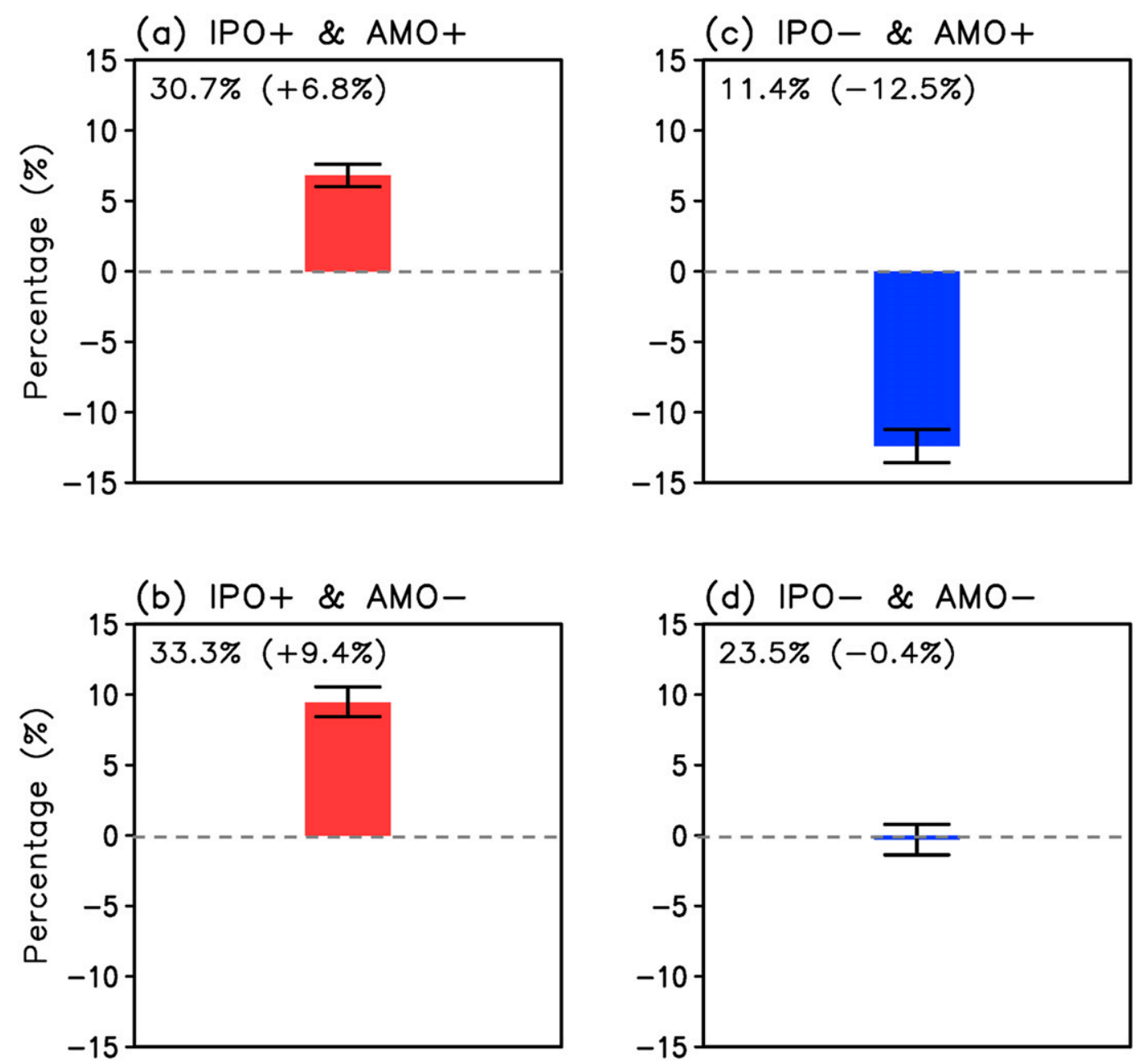

FIG. 5. The percentages of El Niño occurrence (a) during the positive IPO and AMO [i.e., (+) IPO and (+) AMO], (b) during the positive IPO and negative AMO [i.e., (+) IPO and (-) AMO], (c) during the negative IPO and positive AMO [i.e., (-) IPO and (+) AMO], and (d) during the negative IPO and AMO [i.e., (-) IPO and (-) AMO]. The numbers in parentheses are anomalous percentage of El Niño occurrence from climatology. The climatological mean percentage of El Niño occurrence is $23.9 \%$. The error bars indicate $2.5 \%$ lower and $97.5 \%$ upper confidence bounds for each interactive phase using the bootstrap method.

cannot be explained by the linear interocean teleconnection mechanism proposed from the previous studies. Therefore, in the next sections, we further explore the asymmetric AMO-El Niño relationship with respect to the IPO phase and the underlying physical mechanisms.

\section{d. Influences of the interactive IPO-AMO phases on the Pacific atmospheric circulation}

Figure 6 shows the composites of anomalous upperlevel velocity potential and divergent winds for the four interactive IPO-AMO phases. Figures $6 \mathrm{a}$ and $6 \mathrm{~b}$ compare the upper-level divergence response to the AMO during the positive IPO phase. During both the $(+)$ IPO and (+) AMO and (+) IPO and (-) AMO phases, strong anomalous upper-level divergence prevails over the southeast Pacific and along the equatorial Pacific, and it is accompanied by anomalous upper-level convergence over the western Pacific and Indian Ocean. The anomalous upper-level convergence along the equatorial Pacific is not much different between during the (+) IPO and (+) AMO and (+) IPO and (-) AMO phases. In contrast, the anomalous upper-level convergence over the Indian Ocean is enhanced during the $(+)$ IPO and (-) AMO phase compared to the (+) IPO and $(+)$ AMO phase. This is expected because both the (+) IPO and (-) AMO promote anomalous upperlevel convergence over the western Pacific, while both the (-) IPO and (+) AMO tend to produce anomalous upper-level divergence in this region. Similarly, the 
(a) $\mathrm{IPO}+\& \mathrm{AMO}+$

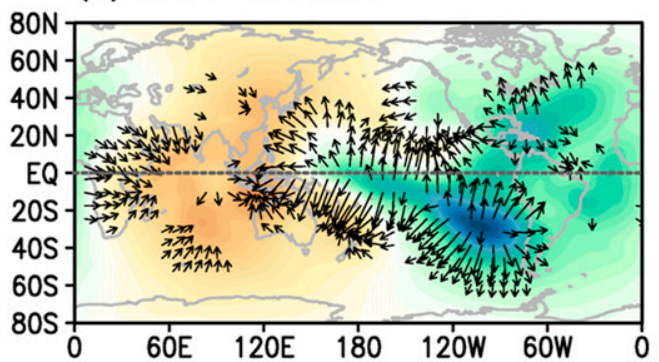

(b) $\mathrm{IPO}+\& \mathrm{AMO}-$

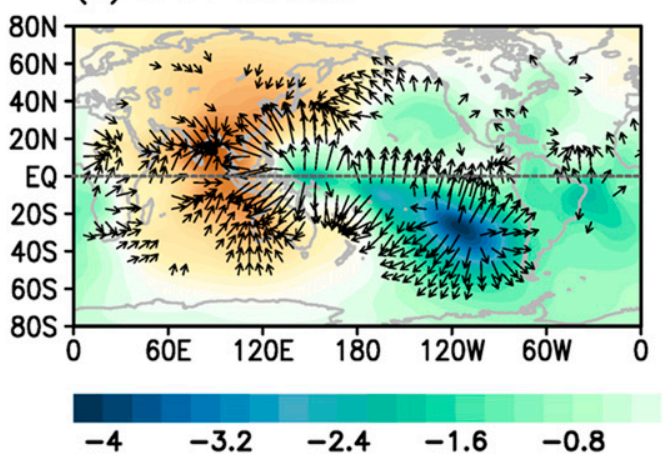

(c) IPO- \& AMO+

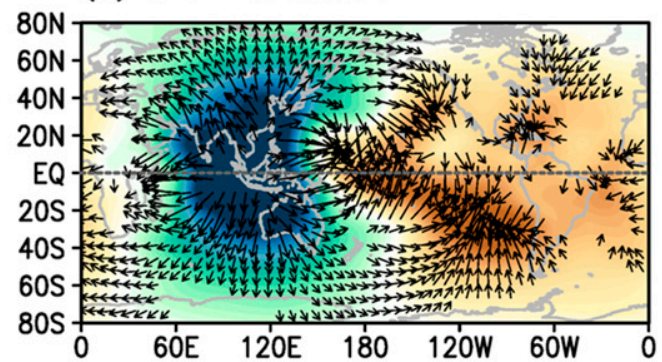

(d) IPO- \& AMO-

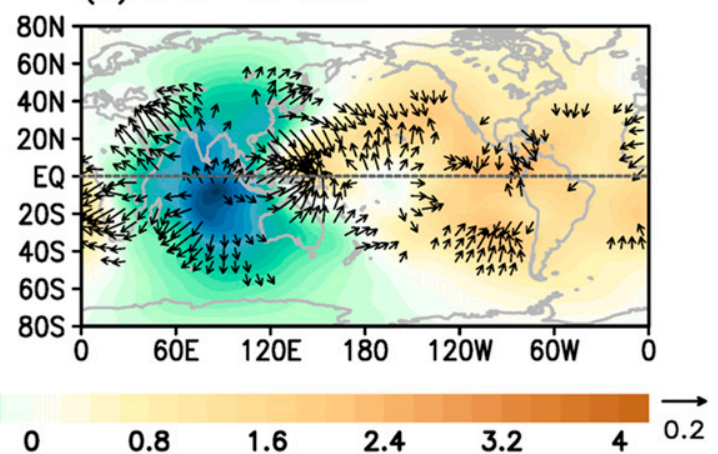

FIG. 6. Composite maps of anomalous 200-hPa velocity potential (shading, $10^{5} \mathrm{~m}^{2} \mathrm{~s}^{-1}$ ) and divergent winds (vectors, $\mathrm{m} \mathrm{s}^{-1}$, omitted below $0.05 \mathrm{~m} \mathrm{~s}^{-1}$ ) corresponding to the four interactive IPO and AMO phases from CESMLENS. (a)-(d) (+) IPO and (+) AMO, (+) IPO and (-) AMO, (-) IPO and (+) AMO, and (-) IPO and (-) AMO, respectively.

anomalous upper-level convergence that appears over the northeast Pacific $\left(0^{\circ}-30^{\circ} \mathrm{N}, 150^{\circ}-100^{\circ} \mathrm{W}\right)$ during the $(+)$ IPO and $(+)$ AMO phase can be explained as a constructive influence of the IPO and AMO over the region. This anomalous upper-level convergence nearly disappears during the (+) IPO and (-) AMO phase due to the compensating influence of the IPO and AMO in the region.

Figures $6 \mathrm{c}$ and $6 \mathrm{~d}$ compare upper-level divergence response to the AMO during the negative IPO phase. During the (-) IPO and (+) AMO phase, strong anomalous upper-level convergence prevails in the southeast Pacific $\left(30^{\circ}-10^{\circ} \mathrm{S}, 100^{\circ}-80^{\circ} \mathrm{W}\right)$ and along the equatorial Pacific, and anomalous upper-level divergence over the Maritime Continent and Indian Ocean (Fig. 6c). Strong anomalous upper-level divergence occurs over the northeast Pacific $\left(0^{\circ}-30^{\circ} \mathrm{N}, 150^{\circ}-100^{\circ} \mathrm{W}\right)$. This appears to be linked to the increased convection and rising motion over the northeastern Pacific $\left(0^{\circ}-\right.$ $15^{\circ} \mathrm{N}, 100^{\circ}-80^{\circ} \mathrm{W}$ ) expected during the positive AMO phase (Fig. 4c). However, this is much stronger, extensive, and shifted to the west. In response to the significantly increased ascending motion and upper-level divergence over the northeast Pacific, strong anomalous upper-level convergence fields develop to the northwest of this region and over the southeast Pacific.
During the (-) IPO and (-) AMO phase, the southeast Pacific and western Pacific warm pool are characterized by weak anomalous upper-level convergence, whereas the Indian Ocean is characterized by weak anomalous upper-level divergence (Fig. 6d). These are expected during the negative IPO phase (Fig. 4a). However, they are considerably weaker compared to those during the (-) IPO and (+) AMO phase (Fig. 6c). Additionally, there is no anomalous upper-level convergence over the central equatorial Pacific, which is inconsistent with the effect of the negative IPO phase. It appears that the expected negative IPO-induced anomalous upper-level convergence over the southeast Pacific and along the equatorial Pacific is suppressed (or canceled) by the remote influence of the negative AMO phase, which is to produce anomalous upper-level divergence over the southeast Pacific and North Pacific (Fig. 4c).

The above analysis indicates that the remote impact of AMO is to reinforce or inhibit the direct impact of IPO on the upper-level divergence response over the Pacific. However, the amplitudes and spatial distributions of the response cannot be explained as the linear sum of the IPO- and AMO-induced responses. In particular, as evident from Fig. 6, the direct and remote influences of 
(a) $\mathrm{IPO}+\& \mathrm{AMO}+$

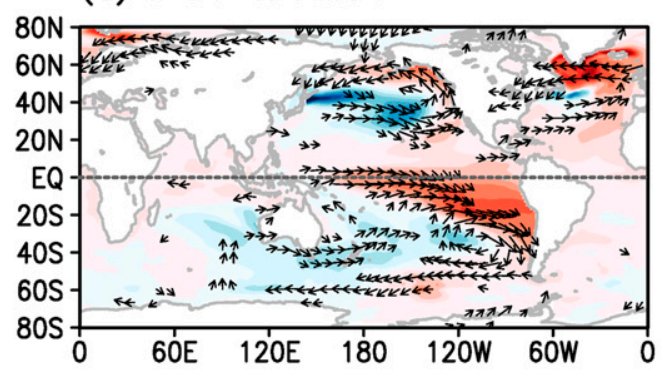

(b) $\mathrm{IPO}+\& \mathrm{AMO}-$

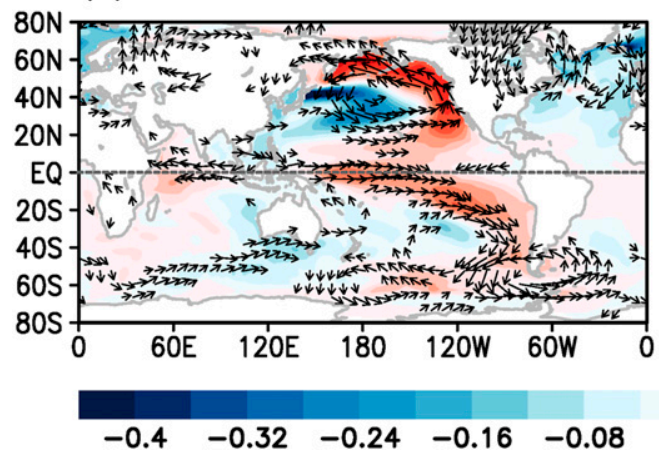

(c) IPO- \& $\mathrm{AMO}+$

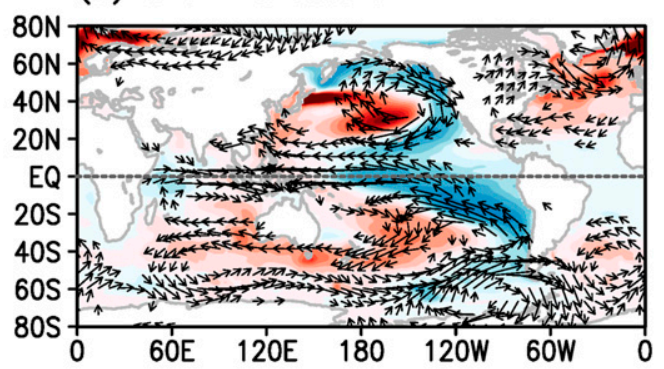

(d) IPO- \& AMO-

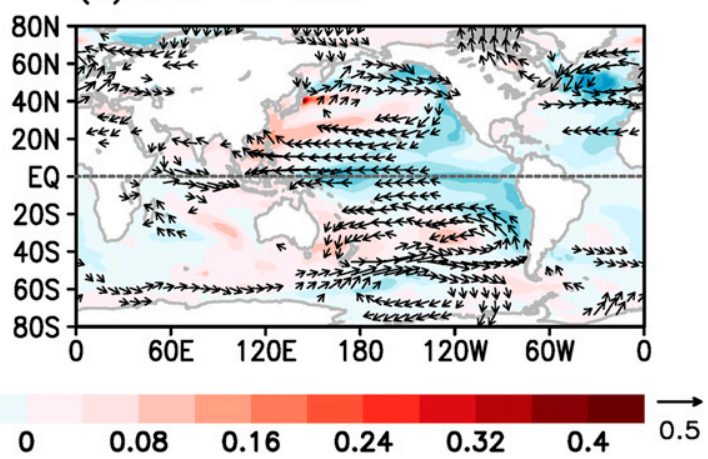

FIG. 7. Composite maps of SSTAs (shading, K) and $850-\mathrm{hPa}$ wind anomalies (vectors, $\mathrm{m} \mathrm{s}^{-1}$, omitted below $0.1 \mathrm{~m} \mathrm{~s}^{-1}$ ) corresponding to the four interactive IPO and AMO phases from CESM-LENS. (a)-(d) (+) IPO and (+) AMO, (+) IPO and (-) AMO, (-) IPO and (+) AMO, and (-) IPO and (-) AMO, respectively.

AMO are much stronger during the negative IPO phase than during the positive IPO phase. This means that the AMO-induced Pacific atmospheric circulation response depends strongly and nonlinearly on the state of the Pacific (i.e., IPO phase).

The upper-level circulation responses to the four interactive IPO-AMO phases are well reflected in the 850-hPa wind anomalies and SSTAs, as shown in Fig. 7. Consistent with the upper-level circulation responses, the Pacific SSTAs and low-level wind anomalies are more strongly determined by the IPO phase, while the North Atlantic SSTAs and low-level wind anomalies are more strongly driven by the AMO phase. Also in line with the upper-level circulation responses, the sensitivity of central equatorial Pacific SSTAs and low-level wind anomalies to the AMO phase is much stronger during the negative IPO phase (Figs. 7c,d) compared to the positive IPO phase (Figs. 7a,b). More specifically, the equatorial Pacific westerly wind anomalies during the positive IPO phase are not very sensitive to the AMO phase.

During the negative IPO phase, on the other hand, the positive AMO tends to produce strong anomalous ascending motion over the northeastern Pacific $\left(0^{\circ}-\right.$ $\left.15^{\circ} \mathrm{N}, 100^{\circ}-80^{\circ} \mathrm{W}\right)$ and anomalous subsidence to the northwest and over the southeast Pacific, as shown in Fig. 6c. This tripole pattern of anomalous vertical motion is closely linked to the development of low-level easterly wind anomalies converging from the northeast and southeast Pacific toward the equatorial Pacific (Fig. 7c). Thus, the equatorial Pacific low-level easterly wind anomalies during the negative IPO phase are greatly enhanced by the positive AMO phase. In comparison to the (-) IPO and (+) AMO phase, the equatorial Pacific low-level easterly wind anomalies are much weaker during the (-) IPO and (-) AMO phase (Fig. 7d). This is because the anomalous subsidence over the southeast Pacific and along the equatorial Pacific expected during the negative IPO phase is suppressed (or canceled) by the remote influence of the negative AMO phase, which is to produce anomalous ascending motions in the southeast Pacific and North Pacific (Fig. 4c).

In summary, the equatorial Pacific SSTAs and lowlevel westerly wind anomalies are overall favorable for El Niño occurrence during the positive IPO phase (Figs. 7a,b) and unfavorable during the negative IPO phase (Figs. 7c,d). However, the influences of AMO on the equatorial Pacific SSTAs and low-level wind anomalies are robust only during the negative IPO phase and very weak during the positive IPO phase. This 
(a) $\mathrm{IPO}+\& \mathrm{AMO}+$

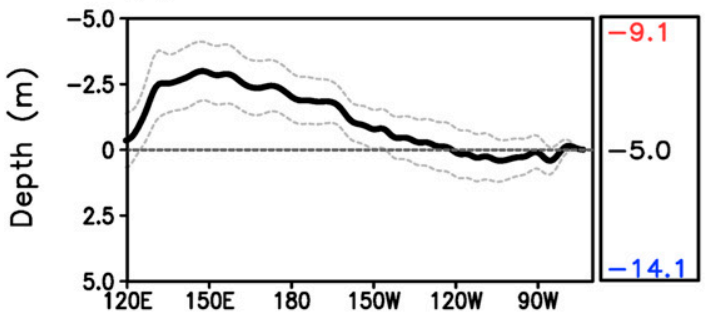

(b) $\mathrm{IPO}+\& \mathrm{AMO}-$

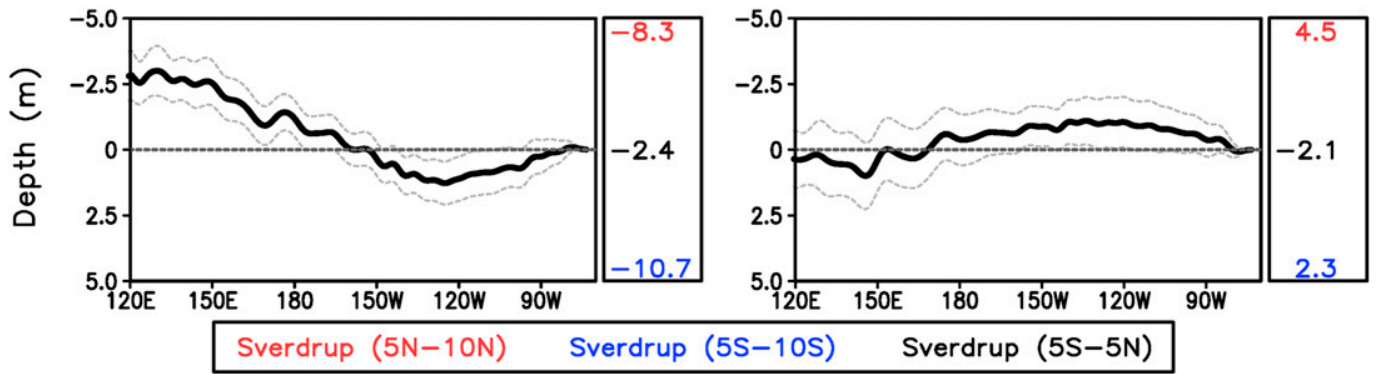

(c) IPO- \& $\mathrm{AMO}+$

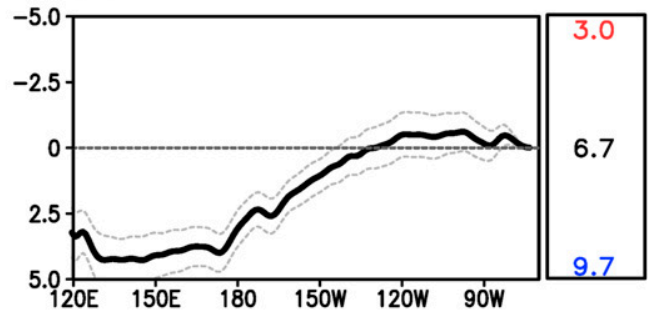

(d) IPO- \& AMO-

FIG. 8. Composite of anomalous equatorial Pacific thermocline depth of $20^{\circ} \mathrm{C}$ isotherm (black solid lines, $\mathrm{m}$ ) corresponding to the four interactive IPO and AMO phases from CESM-LENS. The gray dashed lines indicate \pm one standard deviations of anomalous thermocline depth of $20^{\circ} \mathrm{C}$ isotherm. The numbers in the left panels indicate the spatially averaged meridional Sverdrup transport $\left(\mathrm{m}^{3} \mathrm{~s}^{-1}\right)$. Red, blue, and black colors indicate the Sverdrup transport spatially averaged over $5^{\circ}-10^{\circ} \mathrm{N}, 5^{\circ}-10^{\circ} \mathrm{S}$, and the net Sverdrup transport in the tropic $\left(5^{\circ}-5^{\circ} \mathrm{S}\right)$, respectively. The negative net Sverdrup transport means to flush warm water from the tropic to higher latitude. (a) $-(d)(+)$ IPO and $(+)$ AMO, (+) IPO and (-) AMO, (-) IPO and (+) AMO, and (-) IPO and (-) AMO, respectively.

asymmetric influence of AMO on the equatorial Pacific SSTAs and atmospheric circulation with respect to the IPO phase is consistent with the nonlinear AMO-El Niño relationship shown in Fig. 5. In the next section, we further explore the asymmetric influence of AMO on the equatorial Pacific atmosphere and ocean dynamics.

\section{e. Influences of the interactive IPO-AMO phases on the equatorial Pacific air-sea interaction}

To better understand the influences of the interactive IPO-AMO phases on the equatorial Pacific air-sea interactions related to $\mathrm{El}$ Niño, we investigate equatorial Pacific thermocline depth (i.e., $20^{\circ} \mathrm{C}$ isotherm) anomalies corresponding to the four interactive IPO-AMO phases. As shown in Fig. 8, during the $(+)$ IPO and (+) AMO phase, the thermocline shoals in the western equatorial Pacific (Fig. 8a), consistent with the low-level westerly wind anomalies along the equatorial Pacific (Fig. 7a). During the (+) IPO and (-) AMO phase, the thermocline also shoals in the western equatorial Pacific and deepens slightly in the eastern equatorial Pacific (Fig. 8b). The anomalous zonal slope of the thermocline depth along the equatorial Pacific is about the same in both cases, indicating that the AMO has little impact on the equatorial Pacific thermocline during the positive
IPO phase. This conclusion is consistent with the insensitivity of the equatorial Pacific atmospheric circulation and El Niño occurrence to the AMO during the positive IPO phase, as shown in Figs. 5-7.

It is noted that the overall depth of the equatorial thermocline is shallower during both the $(+)$ IPO and $(+)$ AMO and (+) IPO and (-) AMO phases. The equatorial Pacific low-level westerly wind anomalies and the associated anomalous wind stress curl transport the tropical warm water away from the equator toward higher latitudes. The net meridional Sverdrup transport into the equatorial Pacific $\left(5^{\circ} \mathrm{S}-5^{\circ} \mathrm{N}\right)$ during the $(+)$ IPO and $(+)$ AMO and $(+)$ IPO and ( -$)$ AMO phases are -5.0 and $-2.4 \mathrm{~m}^{3} \mathrm{~s}^{-1}$, respectively. In response to this mass imbalance, the thermocline shoals along the equatorial Pacific.

As shown in Fig. 8c, the equatorial Pacific thermocline deepens greatly in the west during the (-) IPO and $(+)$ AMO phase, consistent with the strong lowlevel easterly wind anomalies along the equatorial Pacific (Fig. 7c). During the (-) IPO and (-) AMO phase, on the other hand, the equatorial Pacific thermocline is nearly unchanged from the climatological mean. These results suggest that the equatorial Pacific thermocline depth is greatly influenced by the AMO 
during the negative IPO phase. It appears that the impact of AMO is sufficiently large that the deepening of the equatorial Pacific thermocline associated with the negative IPO phase can be completely negated by the negative AMO phase (Fig. 8d).

The zonally averaged depth of the equatorial Pacific thermocline is also much deeper during the (-) IPO and (+) AMO. This is because the equatorial Pacific lowlevel easterly wind anomalies and the associated anomalous wind stress curl increase the volume of warm tropical water, which in turn deepens the thermocline along the equatorial Pacific. On the other hand, the zonally averaged depth of the equatorial Pacific thermocline is very close to the climatological mean during the (-) IPO and (-) AMO phases because of the equatorial Pacific low-level easterly wind anomalies (and the associated wind stress curl and Sverdrup transport anomalies) expected from the negative IPO phase is greatly weakened by the negative AMO phase. Consistently, the net meridional Sverdrup transport into the equatorial Pacific during the ( - ) IPO and (+) AMO and ( - IPO and $(-)$ AMO phases are 6.7 and $-2.1 \mathrm{~m}^{3} \mathrm{~s}^{-1}$, respectively.

Our analysis summarized in Fig. 8 indicates that the impact of AMO on the equatorial Pacific thermocline and the associated atmosphere-ocean interaction are robust during the negative IPO phase, but much weaker during the positive IPO phase. This is consistent with the asymmetric AMO-El Niño relationship between the positive and negative IPO phases (Fig. 5). In other words, the influence of AMO on El Niño activity depends critically on the mean state of Pacific, which is modulated by the IPO phase. This also emphasizes the need to further isolate and explore the AMO-El Niño relationship and the associated atmospheric dynamics between the positive and negative IPO phases. Therefore, in the next section, we further explore the AMO-El Niño relationship during the positive and negative IPO phases, separately. To achieve this, we compute the composite differences of the atmospheric circulation anomalies between the positive and negative AMO phases for each of the positive and negative IPO phases, which are referred to as the IPO statedependent AMO impacts. The IPO state-dependent AMO impacts during the positive and negative IPO phases are indicated by $\mathrm{AMO}_{(-) I P O}$ and $\mathrm{AMO}_{(+) I P O}$, respectively.

\section{f. The IPO state-dependent AMO impacts on the Pacific atmospheric circulation}

Figure 9a shows the climatological annual mean patterns of velocity potential and divergent winds at $200 \mathrm{hPa}$ derived from CESM-LENS. The composites of anomalous upper-level velocity potential and divergent winds during the positive (358 years) and negative (299 years) IPO phases are also shown in Figs. 9b and 9c, respectively. Figure 9a clearly shows climatological upper-level divergence centered over the western Pacific warm pool and climatological upper-level convergence centered over the subtropical North and South Atlantic and the southeast Pacific $\left(40^{\circ}-10^{\circ} \mathrm{S}, 120^{\circ}-70^{\circ} \mathrm{W}\right)$. It should be also noted that the northeast Pacific $\left(0^{\circ}-20^{\circ} \mathrm{N}, 140^{\circ}-\right.$ $\left.80^{\circ} \mathrm{W}\right)$ is characterized by climatological upper-level divergence fueled by the Pacific intertropical convergence zone (ITCZ). During the positive IPO phase (Fig. 9b), strong anomalous upper-level divergence appears over the southeast Pacific, weakening the climatological upper-level convergence in this region. Over the northeast Pacific $\left(0^{\circ}-30^{\circ} \mathrm{N}, 150^{\circ}-100^{\circ} \mathrm{W}\right)$, anomalous upper-level convergence also appears during the positive IPO phase, weakening the climatological upperlevel divergence in this region. During the negative IPO phase (Fig. 9c), on the other hand, strong anomalous upper-level convergence appears over the southeast Pacific, reinforcing the climatological upper-level convergence in this region. Over the northeast Pacific, anomalous upper-level divergence also appears during the negative IPO phase, reinforcing the climatological upper-level divergence in this region. These results indicate that the climatological atmospheric circulation over the eastern Pacific $\left(140^{\circ}-80^{\circ} \mathrm{W}\right)$ is enhanced during the negative IPO phase and weakened during the positive IPO phase.

As briefly discussed in the previous section, the IPO state-dependent AMO impacts during the positive and negative IPO phases are computed as the composite differences of the atmospheric circulation anomalies between the positive and negative AMO phases for each of the positive and negative IPO phases [i.e., $\mathrm{AMO}_{(+) I P O}$

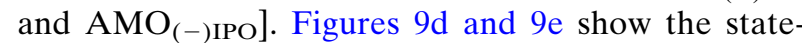
dependent AMO impacts on upper-level velocity potential and divergent winds during the positive and negative IPO phases, respectively. As shown in Fig. 9d, the $\mathrm{AMO}_{(+) I P O}$ is to produce anomalous upper-level divergence, which implies anomalous rising motion, over the northeastern Pacific $\left(0^{\circ}-15^{\circ} \mathrm{N}, 100^{\circ}-80^{\circ} \mathrm{W}\right)$, and anomalous upper-level convergence to the northwest. Anomalous upper-level convergence also appears over the western Pacific warm pool. As shown in Fig. 9e, the $\mathrm{AMO}_{(-) \text {IPO }}$ is to produce strong anomalous upper-level divergence, which implies strong anomalous rising motion, over the northeast Pacific $\left(0^{\circ}-30^{\circ} \mathrm{N}\right.$, $\left.150^{\circ}-100^{\circ} \mathrm{W}\right)$, and anomalous upper-level convergence to the northwest. These impacts are quite similar to the $\mathrm{AMO}_{(+) I P O}$ (Fig. 9d). However, the magnitude of the northeast Pacific $\left(10^{\circ}-30^{\circ} \mathrm{N}, 140^{\circ}-100^{\circ} \mathrm{W}\right)$ upper-level divergence anomalies is much stronger in the $\mathrm{AMO}_{(-) \mathrm{IPO}}$ 
(a) Climatological VP200

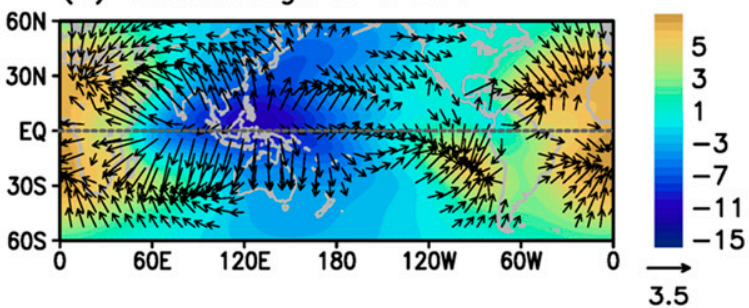

(b) IPO+

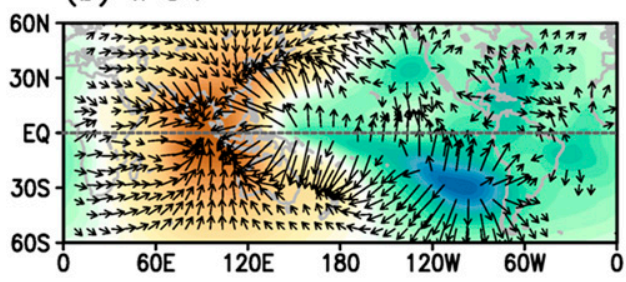

(d) $\mathrm{AMO}_{(+) \text {IPO }}$

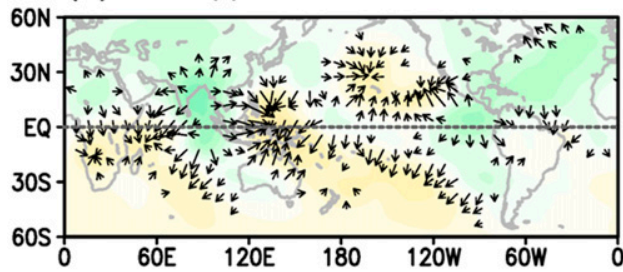

(f) $\mathrm{AMO}_{(+)} \mathrm{PO}$

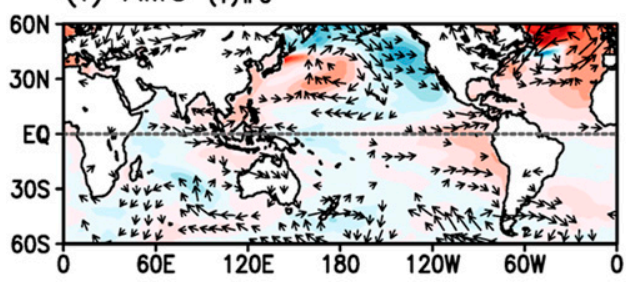

(c) IPO-

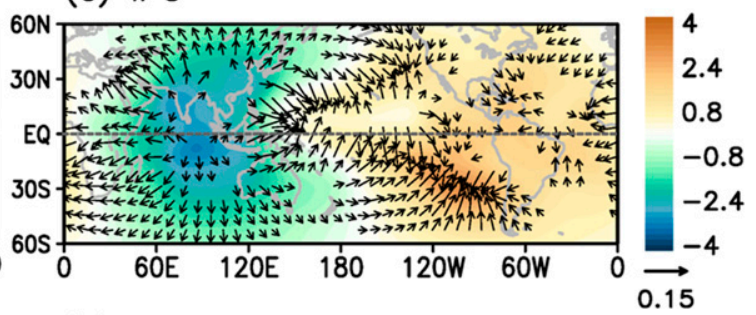

(e) $\mathrm{AMO}_{(-) \text {IPO }}$

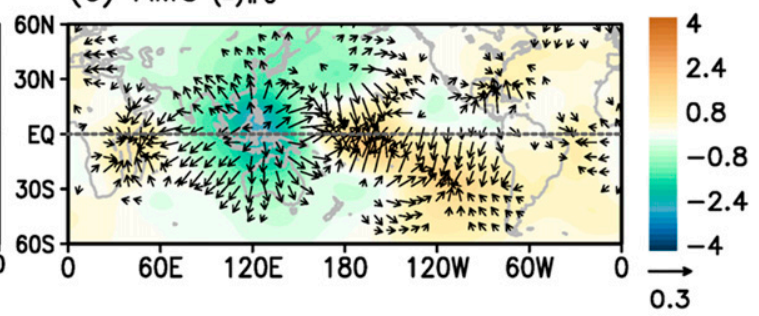

(g) AMO (-) IPO

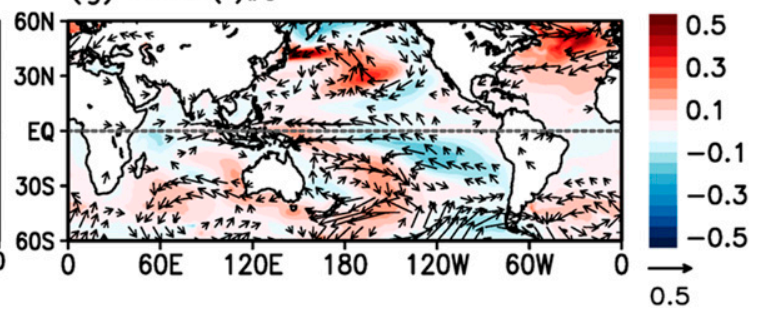

FIG. 9. (a) Annual mean climatology of velocity potential (shading, $10^{5} \mathrm{~m}^{2} \mathrm{~s}^{-1}$ ) and divergence wind at $200 \mathrm{hPa}$ (vectors, $\mathrm{m} \mathrm{s}^{-1}$, omitted below $1.0 \mathrm{~m} \mathrm{~s}^{-1}$ ) from CESM-LENS. (b), (c) Composition map of anomalous velocity potential (shading, $10^{5} \mathrm{~m}^{2} \mathrm{~s}^{-1}$ ) and divergence wind at $200 \mathrm{hPa}$ (vectors, $\mathrm{m} \mathrm{s}^{-1}$, omitted below $0.03 \mathrm{~m} \mathrm{~s}^{-1}$ ) during the positive IPO and the negative IPO, respectively. (d),(e) The positive IPO and the negative IPO state-dependent AMO induced the anomalous velocity potential (shading, $10^{5} \mathrm{~m}^{2} \mathrm{~s}^{-1}$ ) and divergence wind at $200 \mathrm{hPa}$ (vectors, $\mathrm{m} \mathrm{s}^{-1}$, omitted below $0.05 \mathrm{~m} \mathrm{~s}^{-1}$ ), respectively. (f), (g) As in (d),(e), but for SSTAs (shading, K) and 850-hPa winds (vectors, $\mathrm{m} \mathrm{s}^{-1}$, omitted below $0.08 \mathrm{~m} \mathrm{~s}^{-1}$ ).

than the $\mathrm{AMO}_{(+) I P O}$. Additionally, the $\mathrm{AMO}_{(-) I P O}$ also produces strong anomalous upper-level convergence over the southeast Pacific $\left(30^{\circ}-10^{\circ} \mathrm{S}, 100^{\circ}-80^{\circ} \mathrm{W}\right)$ and central equatorial Pacific, which is not observed in the $\mathrm{AMO}_{(+) \mathrm{IPO}}$.

Note that the interhemispheric influence of $\mathrm{AMO}_{(-)}$ IPO on the southeast Pacific and its mechanism have been well documented in previous studies (e.g., Wang et al. 2010; Lee et al. 2013; Ji et al. 2014; Zhang et al. 2014). In particular, Wang et al. (2010) showed that during boreal summer and fall, a regional Hadley-type circulation is established with ascending motion over the northeast Pacific and subsidence over the southeastern tropical Pacific, and that this regional Hadley-type circulation is enhanced when the Atlantic warm pool is anomalously large and reduced when the Atlantic warm pool is anomalously small.

It is also noted that the impact of $\mathrm{AMO}_{(-) \mathrm{IPO}}$ over the Maritime Continent is characterized by anomalous rising motion, consistent with Fig. 4c. However, it is characterized by anomalous sinking motion during the positive IPO phase, inconsistent with Fig. 4c. Given that anomalous upper-level circulation in this region is a 
secondary response to the AMO, it could be sensitive to the strength and location of AMO-induced anomalous subsidence over the North Pacific (Sun et al. 2017) or the interactions between the Atlantic and Indo-Pacific ( $\mathrm{Li}$ et al. 2016). As shown in Fig. 9d, the $\mathrm{AMO}_{(+) I P O}$ is to produce anomalous descending motions over the North Pacific $\left(0^{\circ}-50^{\circ} \mathrm{N}, 180^{\circ}-120^{\circ} \mathrm{W}\right)$ and the western Pacific warm pool, and weak anomalous ascending motion over the central tropical Pacific. This tripole pattern of anomalous vertical motion is a direct result of the statedependent interocean teleconnection impact of AMO during the positive IPO phase, which is much weaker than those during the negative IPO phase.

As shown in Figs. 9f and 9g, the state-dependent AMO impacts on the SSTAs and low-level wind anomalies are also robust during the negative IPO phase and very weak during the positive IPO phase, consistent with the upperlevel atmospheric circulation anomalies (Figs. 9d,e). Specifically, the $\mathrm{AMO}_{(-) \mathrm{IPO}}$ is to produce strong lowlevel easterly wind anomalies over the southeast Pacific $\left(30^{\circ}-10^{\circ} \mathrm{S}, 100^{\circ}-80^{\circ} \mathrm{W}\right)$ and along the western equatorial Pacific, consistent with the anomalous upper-level convergence over these regions (Fig. 9e). The low-level easterly wind anomalies along the western equatorial Pacific are consistent with the anomalous ascending motion over the Maritime Continent and the anomalous descending motion over the central equatorial Pacific (i.e., enhanced Pacific Walker cell). On the other hand, the impact of $\mathrm{AMO}_{(+) I P O}$ on the equatorial Pacific low-level winds is very weak. These results show that the IPO statedependent effects of AMO on the equatorial Pacific lowlevel winds are robust during the negative IPO phase (i.e., El Niño favorable conditions during the negative AMO phase and unfavorable conditions during the positive AMO phase), and very weak during the positive IPO phase.

As summarized in Fig. 9, our analysis indicates that the atmospheric mean state in the Pacific, especially in the northeast and southeast Pacific $\left(140^{\circ}-80^{\circ} \mathrm{W}\right)$, is reinforced (i.e., amplified) during the negative IPO phase and weakened during the positive IPO phase. Similarly, the atmospheric mean state over the Maritime Continent is reinforced during the negative IPO phase and weakened during the positive IPO phase. Coincidently, the state-dependent AMO impacts over the eastern Pacific and the Maritime Continent are amplified during the negative IPO phase and weakened during the positive IPO phase. These results strongly imply that the AMO-induced interocean teleconnections to the eastern Pacific and Maritime Continent are facilitated by the strong and energetic mean state of the negative IPO phase and hindered by the weakened mean state of the positive IPO phase. Consistent with this hypothesis, the effects of $\mathrm{AMO}$ on the equatorial Pacific low-level winds are robust during the negative IPO phase of the enhanced Pacific mean state and very weak during the positive IPO phase of the weakened Pacific mean state.

\section{g. CESM-AGCM experiments associated with the four interactive IPO-AMO phases}

To test the hypothesis proposed in the previous section, we perform four CESM-AGCM experiments under the four interactive IPO-AMO phases, as described in section 2. Figures 10a and 10b show the simulated IPO state-dependent AMO impacts on the upper-level velocity potential and divergent winds during the positive and negative IPO phases, respectively. Despite slight displacements of maximum anomalies, the spatial patterns of the upper-level atmospheric circulation anomalies are quite consistent between CESM-AGCM and CESM-LENS. Both the $\mathrm{AMO}_{(+) I P O}$ and $\mathrm{AMO}_{(-) I P O}$ produce anomalous upper-level divergence and ascending motion over the northeastern Pacific $\left(0^{\circ}-15^{\circ} \mathrm{N}, 100^{\circ}-\right.$ $\left.80^{\circ} \mathrm{W}\right)$ and anomalous upper-level convergence over the southeast Pacific $\left(30^{\circ}-10^{\circ} \mathrm{S}, 100^{\circ}-80^{\circ} \mathrm{W}\right)$. Consistent with the results from CESM-LENS (Fig. 9d), the $\mathrm{AMO}_{(+) I P O}$ generates anomalous upper-level convergence over the western Pacific warm pool. Conversely, the $\mathrm{AMO}_{(-) \mathrm{IPO}}$ generates weak anomalous upper-level divergence south of the western Pacific warm pool $\left(5^{\circ}-20^{\circ} \mathrm{S}, 130^{\circ}-160^{\circ} \mathrm{E}\right)$. It should be noted that active atmosphere-ocean feedback, which is required to induce the secondary response to the AMO over the Maritime Continent (Sun et al. 2017; Li et al. 2016), is missing in CESM-AGCM experiments. Therefore, the impact of AMO over the Maritime Continent is much weaker in CESM-AGCM than in CESM-LENS. The amplitude of northeastern Pacific upper-level divergence anomalies is much higher in the $\mathrm{AMO}_{(-) I P O}$ than the $\mathrm{AMO}_{(+) I P O}$, also consistent with the results from CESM-LENS. In the $\mathrm{AMO}_{(-) \text {IPO, the }}$ enhanced upper-level divergence over the northeastern Pacific leads strong anomalous upper-level convergence over the southeast Pacific and central equatorial Pacific, in agreement with the results from CESM-LENS.

The simulated state-dependent AMO impacts on low-level wind anomalies during the positive and negative IPO phases are shown in Figs. 10c and 10d. In the $\mathrm{AMO}_{(-) \mathrm{IPO}}$, strong anomalous upper-level convergence and subsidence over the southeast Pacific produce strong low-level easterly wind anomalies along the central equatorial Pacific. Consistent with the results from CESM-LENS (Figs. 9f,g), the low-level easterly wind anomalies along the central equatorial Pacific are missing in the $\mathrm{AMO}_{(+) \mathrm{IPO}}$.

However, there are some notable disagreements between the CESM-AGCM and CESM-LENS in the lowlevel wind anomalies. For instance, in both the $\mathrm{AMO}_{(-) \mathrm{IPO}}$ 
(a) $\mathrm{AMO}_{(+) \text {IPO }}$
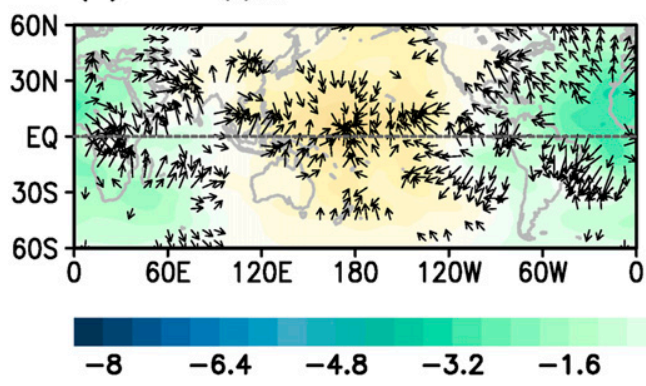

(c) $\mathrm{AMO}(+)$ IPO
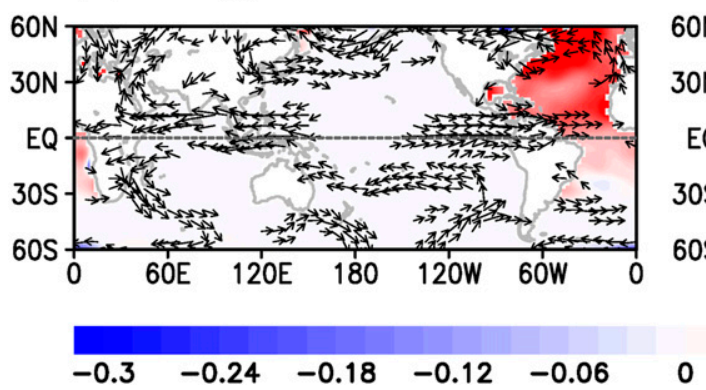

(b) $\mathrm{AMO}(-) \mathrm{PPO}$
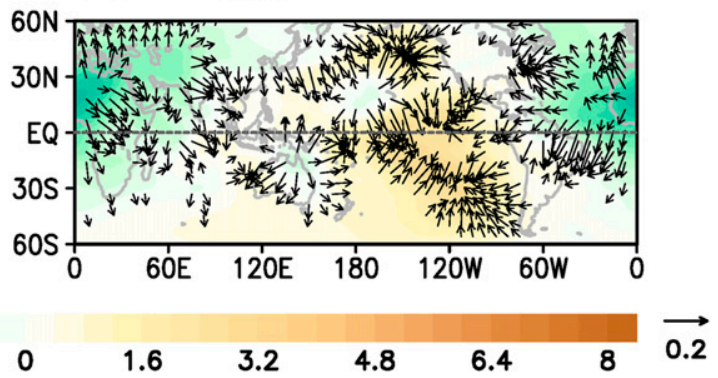

(d) $A M O(-)$ IPO

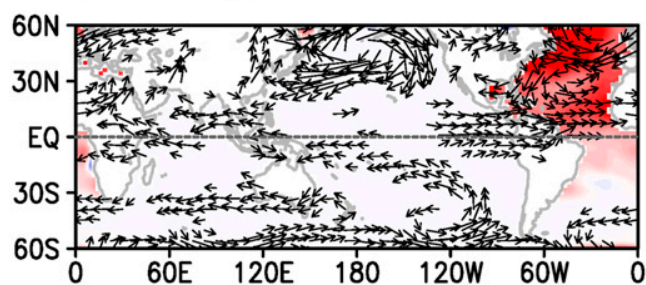

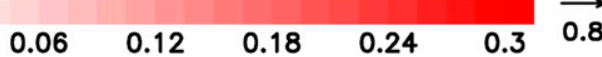

FIG. 10. (a) The positive IPO and (b) negative IPO state-dependent AMO induced the anomalous velocity potential (shading, $10^{5} \mathrm{~m}^{2} \mathrm{~s}^{-1}$ ) and divergence wind at $200 \mathrm{hPa}$ (vectors, $\mathrm{m} \mathrm{s}^{-1}$, omitted below $0.05 \mathrm{~m} \mathrm{~s}^{-1}$ ) in CESMAGCMs, respectively. (c),(d) As in (a),(b), but for SSTAs (shading, K) and 850-hPa winds (vectors, $\mathrm{m} \mathrm{s}^{-1}$, omitted below $0.08 \mathrm{~m} \mathrm{~s}^{-1}$ ).

and $\mathrm{AMO}_{(+) I P O}$, strong low-level westerly wind anomalies appear over the eastern tropical Pacific, which are not clearly observed in the CESM-LENS. Additionally, the $\mathrm{AMO}_{(-) I P O}$ produces strong low-level anticyclonic circulation anomaly over the midlatitude North Pacific $\left(30^{\circ}-60^{\circ} \mathrm{N}, 150^{\circ} \mathrm{E}-130^{\circ} \mathrm{W}\right)$, while the $\mathrm{AMO}_{(+) \text {IPO }}$ produces weaker low-level anticyclonic circulation anomaly over the higher latitudes (poleward of $50^{\circ} \mathrm{N}$ and $150^{\circ} \mathrm{E}-$ $130^{\circ} \mathrm{W}$ ). These results are not observed in the CESMLENS. Apparently, these disagreements between the CESM-AGCM and CESM-LENS are owing to the lack of atmosphere-ocean feedbacks in the CESM-AGCM. Despite these disagreements in the low-level wind anomalies, the sensitivity experiments generally support our main conclusion that the impact of AMO on the tropical Pacific atmospheric circulations, which in turn modulates El Niño frequency, is much stronger during the negative IPO phase [i.e., $\mathrm{AMO}_{(-) I P O}$ ] compared to the positive IPO phase [i.e., $\mathrm{AMO}_{(+) I P O}$.

\section{h. Pacific control of the AMO-El Niño relationship}

Figure 11 summaries the above proposed mechanism of the IPO state-dependent AMO impact in more detail. During the negative IPO phase, the climatological ascending motion from the northeastern Pacific and descending motion into the southeast Pacific are much strengthened. The increased ascending motion from the northeastern Pacific bolsters the state-dependent impact of AMO to further enhance the ascending motion, which in turn also further enhances the increased descending motion into the southeast Pacific through enhanced local anomalous Hadley circulation. The enhanced subsidence into the southeast Pacific increases the low-level easterly wind anomalies along the central equatorial Pacific, which is unfavorable for El Niño occurrence (Fig. 11b).

Note that this mechanism is also applicable to the negative AMO phase, which is to strongly suppress the ascending motion from the northeastern Pacific and descending motion into the southeast Pacific, due to the enhanced eastern Pacific mean state. The suppressed subsidence into the southeast Pacific decreases the lowlevel easterly wind anomalies along the central equatorial Pacific, which is favorable for El Niño occurrence. As illustrated in Fig. 11c, during the positive IPO phase, on the other hand, the climatological ascending motion from the northeastern Pacific and descending motion into the southeast Pacific are much weakened. The weakened mean state over the eastern Pacific hinders the state-dependent impact of AMO on the Pacific atmospheric circulation. Therefore, neither the positive nor negative AMO phase has significant impact on the frequency of El Niño during the positive IPO phase. 
(a) Climatology

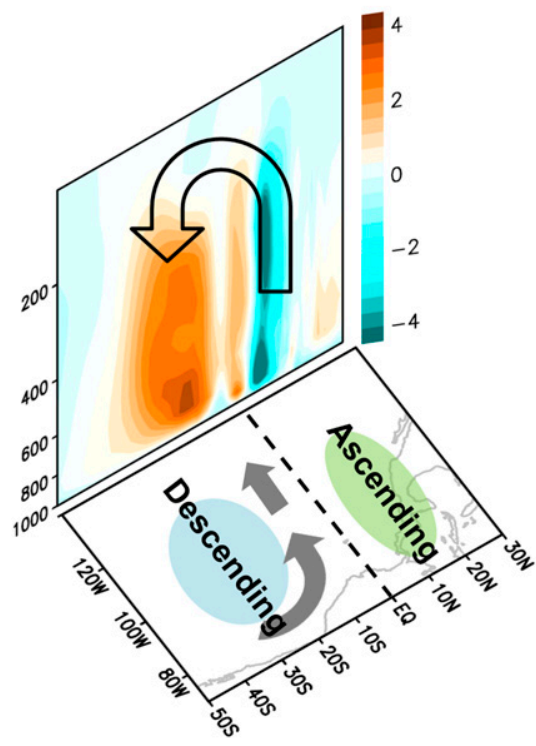

(b) $\mathrm{AMO}(-)$ IPO

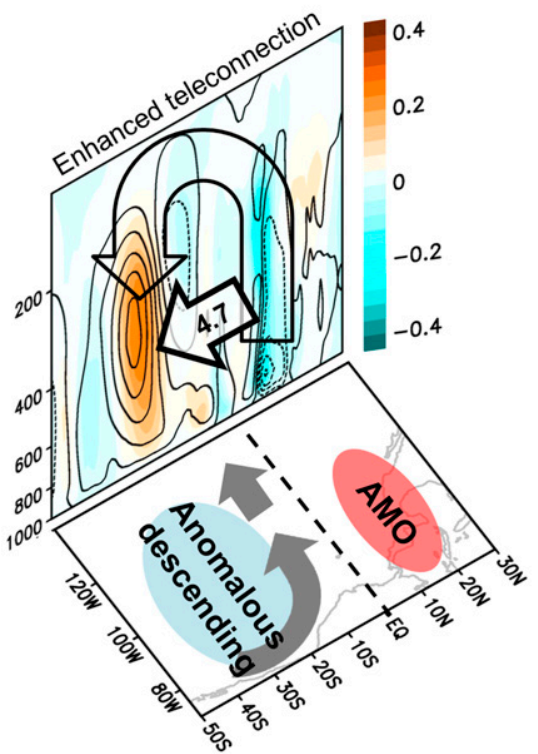

(c) $\mathrm{AMO}(+) \mathrm{IPO}$

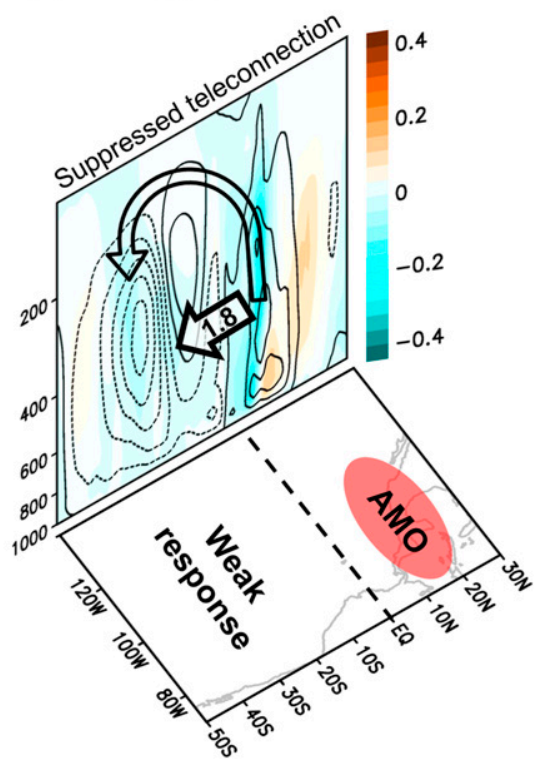

FIG. 11. (a) Schematic diagrams of spatially averaged $\left(140^{\circ}-80^{\circ} \mathrm{W}\right)$ climatological vertical motion (shading, $100 \mathrm{~Pa} \mathrm{~s}^{-1}$, the negative value is ascending motion) and low-level winds (gray filled arrows in the lying panel) over the eastern Pacific. (b) The anomalous vertical motion during the negative IPO (shading, $100 \mathrm{~Pa} \mathrm{~s}^{-1}$ ), the negative IPO state-dependent AMO-induced vertical motion (contour lines, contour level is $\left.0.2 \mathrm{~Pa} \mathrm{~s}^{-1}\right)$, the negative IPO state-dependent AMO-induced spatial average $\left(30^{\circ} \mathrm{S}-30^{\circ} \mathrm{N}, 140^{\circ}-80^{\circ} \mathrm{W}\right)$ of the integrated atmospheric mass transport from 700 to $100 \mathrm{hPa}$ (black arrows, $10^{9} \mathrm{~kg} \mathrm{~s}^{-1}$ ), and the negative IPO state-dependent AMO-induced atmospheric circulation (gray arrows). (c) As in (b), but for the positive IPO state-dependent AMO impact.

Although not explicitly illustrated in Fig. 11, during the negative IPO phase, the climatological ascending motion over the Maritime Continent is also much strengthened (Fig. 9c). This in turn strengthens the statedependent impact of AMO to further enhance the ascending motion over the Maritime Continent, and thus reinforces the low-level easterly wind anomalies along the central equatorial Pacific. During the positive IPO phase, on the other hand, the climatological ascending motion over the Maritime Continent is much weakened (Fig. 9b). The weakened mean state over the Maritime Continent suppresses the state-dependent impact of AMO to further weaken the ascending motion over the Maritime Continent and its influence on the low-level wind anomalies along the central equatorial Pacific.

\section{Summary and discussion}

To better understand the low-frequency modulation of El Niño activity, this study explores the interactive influences of the IPO and AMO on the equatorial Pacific atmosphere-ocean processes, using CESM-LENS. Our analysis shows that the individual impact of IPO and AMO on El Niño occurrence and the underlying atmosphere-ocean processes agree well with previous studies. However, our composite analysis for the four interactive IPO-AMO phases reveals that the modulating impact of AMO on El Niño occurrence is robust during the negative IPO phase $[\sim 12.1 \%$ decrease from the $(-)$ to $(+)$ AMO phase] but very weak during the positive IPO phase $[\sim 2.6 \%$ decrease from the $(-)$ to $(+)$ AMO phase]. We further analyze this asymmetric AMO-El Niño relationship with respect to the IPO phase, which is termed the IPO state-dependent impact of AMO, to conclude that the AMO-induced interocean teleconnections are facilitated by the enhanced Pacific mean state during the negative IPO phase and hindered by the weakened Pacific mean state during the positive IPO phase.

More specifically, during the negative IPO phase, the increased ascending motion from the northeastern Pacific bolsters the state-dependent impact of AMO to further enhance the ascending motion, which in turn also further enhances the increased descending motion into the southeast Pacific through enhanced local anomalous Hadley circulation. The enhanced subsidence into the southeast Pacific increases the low-level easterly wind anomalies along the central equatorial Pacific, which is unfavorable for El Niño occurrence. Additionally, the enhanced ascending motion over the Maritime Continent strengthens the state-dependent impact of AMO to further enhance the ascending motion over the Maritime Continent and thus reinforces the low-level easterly wind 
anomalies along the central equatorial Pacific. During the positive IPO phase, on the other hand, the weakened mean state over the Pacific hinders the state-dependent impact of AMO on the Pacific atmospheric circulation and the frequency of El Niño.

The major finding in this study is that the AMO-El Niño relationship and the associated interocean teleconnections may depend critically on the Pacific mean state, which is modulated largely by the IPO. This Pacific state modulation of the interocean teleconnection may be also applicable to both interannual and centennial time scales. For example, recent studies have shown that a large Atlantic warm pool in boreal summer tends to suppress El Niño development (Ham et al. 2013; Cai et al. 2019; Park et al. 2019). Another example is for the future climate projection. The climate models used in CMIP5 project a substantial weakening of the Walker circulation and thus the equatorial trade winds (e.g., Vecchi and Soden 2007). Consequently, the eastern equatorial Pacific is characterized by accelerated warming and precipitation (Liu et al. 2005; IPCC 2013; Cai et al. 2015). The enhanced precipitation and ascending motion over the eastern equatorial Pacific reinforce the descending motion into the southeast Pacific, suppressing the atmospheric convection and warming in the southeast Pacific (Ma and Xie 2013; IPCC 2013). This positive IPO-like eastern Pacific mean state is commonly observed in the CMIP5 model simulations for the future greenhouse gas emission scenarios, and it may influence the interocean teleconnection and its impact on El Niño occurrence. Additionally, the Atlantic meridional overturning circulation (AMOC) may slow down in the future causing a negative AMO-like mean state in the North Atlantic (e.g., Cheng et al. 2013), and thus may also influence El Niño occurrence in the future.

It is important to discuss several limitations in this study. First, despite good agreements with previous studies and with ERA20, our findings are based on a single model (CESM). Therefore, it is possible that the spatial distribution and magnitude of IPO- and AMOinduced changes in atmospheric circulations and $\mathrm{El}$ Niño occurrences may change in different models. For example, CESM-LENS has cold tropical North Atlantic (TNA) SST bias, which is a common problem in CMIP5 models (e.g., Wang et al. 2014; Zhang et al. 2014). This systematic bias suppresses the local Hadley cell from the TNA to the southeastern Pacific. It may modulate the sensitivity of asymmetric impact of AMO on El Niño frequency. Therefore, in future work, the IPO state-dependent AMO-El Niño relationship should be reinvestigated in a multimodel framework. Additionally, some studies (d'Orgeville and Peltier 2007; Zhang and Delworth 2007; Zanchettin et al. 2016; Levine et al. 2017) suggested that the IPO and AMO are not entirely independent processes. For instance, d'Orgeville and Peltier (2007) showed that the AMO leads the IPO by 15-17 years in observational records, although the lead-lag correlation values are not significant at the $5 \%$ level. In CESM-LENS, however, there is no lead-lag correlation (i.e., $-0.2 \leq r \leq 0.2$ ) between the AMO and IPO, consistent with other climate model studies (e.g., Park and Latif 2010). Thus, the IPO and AMO are treated as independent processes in this study. Nevertheless, further study is needed to explore any potential feedback between the AMO and IPO and their modulations of El Niño frequency.

Additionally, although we did not emphasize in this study, the IPO-El Niño relationship can be also affected by AMO conditions. For example, the AMO statedependent IPO impact on the Pacific atmospheric circulations is stronger during a positive AMO phase than a negative AMO phase (not shown). This is likely due to the increased subsidence over the southeast Pacific and the enhanced upper-level divergence over the Maritime Continent during a positive AMO phase that reinforce the Pacific mean states and thus amplify the IPO impact, and vice versa during a negative AMO phase. Therefore, a further study is needed to explore the AMO state-dependent IPO impacts on El Niño frequency. Finally, the mechanism proposed in this study may influence not only the frequency of El Niño but also the strength and spatiotemporal evolutions of El Niño (i.e., El Niño diversity), which are closely tied to global climate and weather variability (e.g., Yeh et al. 2014; Capotondi et al. 2015; Timmermann et al. 2018). Therefore, to further our study, future studies may examine the impact of interactive IPO-AMO phases on El Niño diversity.

Acknowledgments. We would like to sincerely thank anonymous reviewers and Rong Zhang for their thorough reviews and thoughtful comments and suggestions, which led to a significant improvement of the paper. We also would like to thank Greg Foltz for helpful comments and suggestions. ERA20 data were provided by ECMWF (2013). CESM-LENS data were provided by Kay et al. (2015). This work was supported by NOAA's Climate Program Office, Climate Variability and Predictability Program (Award GC16-207), and NOAA's Atlantic Oceanographic and Meteorological Laboratory.

\section{REFERENCES}

Cai, W., and Coauthors, 2015: ENSO and greenhouse warming. Nat. Climate Change, 5, 849-859, https://doi.org/10.1038/nclimate2743. , and Coauthors, 2019: Pantropical climate interactions. Science, 363, eaav4236, https://doi.org/10.1126/science.aav4236. 
Camargo, S. J., and A. H. Sobel, 2005: Western North Pacific tropical cyclone intensity and ENSO. J. Climate, 18, 29963006, https://doi.org/10.1175/JCLI3457.1.

—, K. A. Emanuel, and A. H. Sobel, 2007: Use of a genesis potential index to diagnose ENSO effects on tropical cyclone genesis. J. Climate, 20, 4819-4834, https://doi.org/10.1175/ JCLI4282.1.

Capotondi, A., and Coauthors, 2015: Understanding ENSO diversity. Bull. Amer. Meteor. Soc., 96, 921-938, https://doi.org/ 10.1175/BAMS-D-13-00117.1.

Chen, W., J. Feng, and R. Wu, 2013: Roles of ENSO and PDO in the link of the East Asian winter monsoon to the following summer monsoon. J. Climate, 26, 622-635, https://doi.org/ 10.1175/JCLI-D-12-00021.1.

Cheng, W., J. C. Chiang, and D. Zhang, 2013: Atlantic meridional overturning circulation (AMOC) in CMIP5 models: RCP and historical simulations. J. Climate, 26, 7187-7197, https:// doi.org/10.1175/JCLI-D-12-00496.1.

Danabasoglu, G., S. C. Bates, B. P. Briegleb, S. R. Jayne, M. Jochum, W. G. Large, S. Peacock, and S. G. Yeager, 2012: The CCSM4 ocean component. J. Climate, 25, 1361-1389, https://doi.org/10.1175/JCLI-D-11-00091.1.

Dong, B., and R. T. Sutton, 2007: Enhancement of ENSO variability by a weakened Atlantic thermohaline circulation in a coupled GCM. J. Climate, 20, 4920-4939, https://doi.org/ 10.1175/JCLI4284.1.

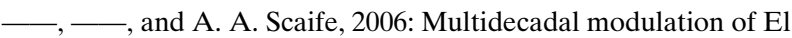
Niño-Southern Oscillation (ENSO) variance by Atlantic Ocean sea surface temperatures. Geophys. Res. Lett., 33, L08705, https://doi.org/10.1029/2006GL025766.

d'Orgeville, M., and W. R. Peltier, 2007: On the Pacific decadal oscillation and the Atlantic multidecadal oscillation: Might they be related? Geophys. Res. Lett., 34, L23705, https:// doi.org/10.1029/2007GL031584.

ECMWF, 2013: ERA-20C project. Meteorological Archival and Retrieval System on ECMWF, accessed 1 December 2018, https:/www.ecmwf.int/en/forecasts/datasets/reanalysis-datasets/ era-20c.

Enfield, D. B., A. M. Mestas-Nunez, and P. J. Trimble, 2001: The Atlantic multidecadal oscillation and its relationship to rainfall and river flows in the continental U.S. Geophys. Res. Lett., 28, 2077-2080, https://doi.org/10.1029/2000GL012745.

Feng, J., W. Chen, C.-Y. Tam, and W. Zhou, 2011: Different impacts of El Niño and El Niño Modoki on China rainfall in the decaying phases. Int. J. Climatol., 31, 2091-2101, https:// doi.org/10.1002/joc.2217.

—, L. Wang, and W. Chen, 2014: How does the East Asian summer monsoon behave in the decaying phase of El Niño during different PDO phases? J. Climate, 27, 2682-2698, https://doi.org/10.1175/JCLI-D-13-00015.1.

Folland, C. K., J. A. Renwick, M. J. Salinger, and A. B. Mullan, 2002: Relative influences of the interdecadal Pacific oscillation and ENSO on the South Pacific convergence zone. Geophys. Res. Lett., 29, 1643, https://doi.org/10.1029/2001GL014201.

Ham, Y.-G., J.-S. Kug, J.-Y. Park, and F.-F. Jin, 2013: Sea surface temperature in the north tropical Atlantic as a trigger for El Niño/Southern Oscillation events. Nat. Geosci., 6, 112-116, https://doi.org/10.1038/ngeo1686.

Henley, B. J., M. A. Thyer, and G. Kuczera, 2013: Climate driver informed short-term drought risk evaluation. Water Resour. Res., 49, 2317-2326, https://doi.org/10.1002/wrcr.20222.

— Folland, 2015: A tripole index for the interdecadal Pacific oscillation. Climate Dyn., 45, 3077-3090, https://doi.org/ 10.1007/s00382-015-2525-1.

Hoell, A., M. Hoerling, J. Eischeid, K. Wolter, R. Dole, J. Perlwitz, and L. Cheng, 2016: Does El Niño intensity matter for California precipitation? Geophys. Res. Lett., 43, 819-825, https://doi.org/10.1002/2015GL067102.

Huang, B., and Coauthors, 2017: Extended reconstructed sea surface temperature, version 5 (ERSSTv5): Upgrades, validations, and intercomparisons. J. Climate, 30, 8179-8205, https:// doi.org/10.1175/JCLI-D-16-0836.1.

IPCC, 2013: Climate Change 2013: The Physical Science Basis. Cambridge University Press, 1535 pp., https://doi.org/10.1017/ CBO9781107415324.

Ji, X., J. D. Neelin, S.-K. Lee, and C. R. Mechoso, 2014: Interhemispheric teleconnections from tropical heat sources in intermediate and simple models. J. Climate, 27, 684-697, https://doi.org/10.1175/JCLI-D-13-00017.1.

Jong, B.-T., M. Ting, and R. Seager, 2016: El Niño's impact on California precipitation: Seasonality, regionality, and El Niño intensity. Environ. Res. Lett., 11, 054021, https://doi.org/ 10.1088/1748-9326/11/5/054021.

Kaplan, A., M. Cane, Y. Kushnir, A. Clement, M. Blumenthal, and B. Rajagopalan, 1998: Analyses of global sea surface temperature 1856-1991. J. Geophys. Res., 103, 18567-18589, https://doi.org/10.1029/97JC01736.

Kay, J., and Coauthors, 2015: The Community Earth System Model (CESM) Large Ensemble Project: A community resource for studying climate change in the presence of internal climate variability. Bull. Amer. Meteor. Soc., 96, 1333-1349, https:// doi.org/10.1175/BAMS-D-13-00255.1.

Khedun, C. P., A. K. Mishra, V. P. Singh, and J. R. Giardino, 2014: A copula-based precipitation forecast model: Investigating the interdecadal modulation of ENSO's impact on monthly precipitation. Water Resour. Res., 50, 580-600, https://doi.org/ 10.1002/2013WR013763.

Kiem, A. S., S. W. Franks, and G. Kuczera, 2003: Multi-decadal variability of flood risk. Geophys. Res. Lett., 30, 1035, https:// doi.org/10.1029/2002GL015992.

Kim, H., M. Lee, P. J. Webster, D. Kim, and J. H. Yoo, 2013: A physical basis for the probabilistic prediction of the accumulated tropical cyclone kinetic energy in the western North Pacific. J. Climate, 26, 7981-7991, https://doi.org/10.1175/ JCLI-D-12-00679.1.

Lee, S.-K., C. R. Mechoso, C. Wang, and J. D. Neelin, 2013: Interhemispheric influence of the northern summer monsoons on the southern subtropical anticyclones. J. Climate, 26, 10 193-10 204, https://doi.org/10.1175/JCLI-D-13-00106.1.

, B. E. Mapes, C. Wang, D. B. Enfield, and S. J. Weaver, 2014: Springtime ENSO phase evolution and its relation to rainfall in the continental U.S. Geophys. Res. Lett., 41, 1673-1680, https://doi.org/10.1002/2013GL059137.

- H. Lopez, E.-S. Chung, P. DiNezio, S.-W. Yeh, and A. T. Wittenberg, 2018: On the fragile relationship between El Niño and California rainfall. Geophys. Res. Lett., 45, 907-915, https://doi.org/10.1002/2017GL076197.

Levine, A. F. Z., M. J. McPhaden, and D. M. W. Frierson, 2017: The impact of the AMO on multidecadal ENSO variability. Geophys. Res. Lett., 44, 3877-3886, https://doi.org/10.1002/2017GL072524.

—, D. M. W. Frierson, and M. J. McPhaden, 2018: AMO forcing of multidecadal Pacific ITCZ variability. J. Climate, 31, 57495764, https://doi.org/10.1175/JCLI-D-17-0810.1.

Li, R. C., and W. Zhou, 2012: Changes in western Pacific tropical cyclones associated with the El Niño-Southern Oscillation 
cycle. J. Climate, 25, 5864-5878, https://doi.org/10.1175/ JCLI-D-11-00430.1.

Li, X., S.-P. Xie, S. T. Gille, and C. Yoo, 2016: Atlantic-induced pantropical climate change over the past three decades. Nat. Climate Change, 6, 275-279, https://doi.org/10.1038/nclimate2840.

Lin, R., F. Zheng, and X. Dong, 2018: ENSO frequency asymmetry and the Pacific decadal oscillation in observations and 19 CMIP5 models. Adv. Atmos. Sci., 35, 495-506, https://doi.org/ 10.1007/s00376-017-7133-z.

Liu, Z., S. Vavrus, F. He, N. Wen, and Y. Zhong, 2005: Rethinking tropical ocean response to global warming: The enhanced equatorial warming. J. Climate, 18, 4684-4700, https://doi.org/ 10.1175/JCLI3579.1.

Lopez, H., and B. P. Kirtman, 2018: ENSO influence over the Pacific North American sector: Uncertainty due to atmospheric internal variability. Climate Dyn., 52, 6149-6172, https://doi.org/10.1007/s00382-018-4500-0.

Ma, J., and S.-P. Xie, 2013: Regional patterns of sea surface temperature change: A source of uncertainty in future projections of precipitation and atmospheric circulation. J. Climate, 26, 2482-2501, https://doi.org/10.1175/JCLI-D-12-00283.1.

Mantua, N. J., S. R. Hare, Y. Zhang, J. M. Wallace, and R. C. Francis, 1997: A Pacific interdecadal climate oscillation with impacts on salmon production. Bull. Amer. Meteor. Soc., 78 , 1069-1079, https://doi.org/10.1175/1520-0477(1997)078<1069: APICOW $>2.0 . C O ; 2$.

Newman, M., and Coauthors, 2016: The Pacific decadal oscillation, revisited. J. Climate, 29, 4399-4427, https://doi.org/10.1175/ JCLI-D-15-0508.1.

Park, J. H., T. Li, S. W. Yeh, and H. Kim, 2019: Effect of recent Atlantic warming in strengthening Atlantic-Pacific teleconnection on interannual timescale via enhanced connection with the Pacific meridional mode. Climate Dyn., 53, 371-387, https://doi.org/10.1007/s00382-018-4591-7.

Park, W., and M. Latif, 2010: Pacific and Atlantic multidecadal variability in the Kiel Climate Model. Geophys. Res. Lett., 37, L24702, https://doi.org/10.1029/2010GL045560.

Poli, P., and Coauthors, 2016: ERA-20C: An atmospheric reanalysis of the twentieth century. J. Climate, 29, 4083-4097, https://doi.org/10.1175/JCLI-D-15-0556.1.

Power, S., T. Casey, C. Folland, A. Colman, and V. Mehta, 1999: Inter-decadal modulation of the impact of ENSO on Australia. Climate Dyn., 15, 319-324, https://doi.org/10.1007/ s003820050284.

Sun, C., F. Kucharski, J. Li, F.-F. Jin, I.-S. Kang, and R. Ding, 2017: Western tropical Pacific multidecadal variability forced by the Atlantic multidecadal oscillation. Nat. Commun., 8, 15998, https://doi.org/10.1038/ncomms15998.

Sung, M.-K., S.-I. An, B.-M. Kim, and J.-S. Kug, 2015: Asymmetric impact of Atlantic multidecadal oscillation on El Niño and La Niña characteristics. Geophys. Res. Lett., 42, 4998-5004, https://doi.org/10.1002/2015GL064381.

Timmermann, A., and Coauthors, 2007: The influence of a weakening of the Atlantic meridional overturning circulation on ENSO. J. Climate, 20, 4899-4919, https://doi.org/10.1175/JCLI4283.1.

—, and Coauthors, 2018: El Niño-Southern Oscillation complexity. Nature, 559, 535-545, https://doi.org/10.1038/s41586-018-0252-6.

Vecchi, G. A., and B. J. Soden, 2007: Global warming and the weakening of the tropical circulation. J. Climate, 20, 43164340, https://doi.org/10.1175/JCLI4258.1.
Verdon, D., and S. Franks, 2007: Long-term drought risk assessment in the Lachlan River valley-A paleoclimate perspective. Australas. J. Water Res., 11, 145-152, https://doi.org/ 10.1080/13241583.2007.11465319.

Wang, B., and Z. Fan, 1999: Choice of South Asian summer monsoon indices. Bull. Amer. Meteor. Soc., 80, 629-638, https://doi.org/ 10.1175/1520-0477(1999)080<0629:COSASM > 2.0.CO;2.

Wang, C., S.-K. Lee, and C. R. Mechoso, 2010: Inter-hemispheric influence of the Atlantic warm pool on the southeastern Pacific. J. Climate, 23, 404-418, https://doi.org/ 10.1175/2009JCLI3127.1.

— , L. Zhang, S.-K. Lee, L. Wu, and C. R. Mechoso, 2014: A global perspective on CMIP5 climate model biases. Nat. Climate Change, 4, 201-205, https://doi.org/10.1038/nclimate2118.

Wang, L., W. Chen, and R. Huang, 2008: Interdecadal modulation of PDO on the impact of ENSO on the East Asian winter monsoon. Geophys. Res. Lett., 35, L20702, https://doi.org/ 10.1029/2008GL035287.

Westra, S., B. Renard, and M. Thyer, 2015: The ENSOprecipitation teleconnection and its modulation by the interdecadal Pacific oscillation. J. Climate, 28, 4753-4773, https://doi.org/10.1175/JCLI-D-14-00722.1.

Wu, L., B. Wang, T. Li, and R. Huang, 2014: ENSO-phase dependent TD and MRG wave activity in the western North Pacific. Climate Dyn., 42, 1217-1227, https://doi.org/10.1007/ s00382-013-1754-4.

—_, H. Zhang, J. Chen, and T. Feng, 2018: Impact of two types of El Niño on tropical cyclones over the western North Pacific: Sensitivity to location and intensity of Pacific warming. J. Climate, 31, 1725-1742, https://doi.org/10.1175/ JCLI-D-17-0298.1.

Wu, R., Z. Hu, and B. Kirtman, 2003: Evolution of ENSO-related rainfall anomalies in East Asia. J. Climate, 16, 3742-3758, https://doi.org/10.1175/1520-0442(2003)016<3742:EOERAI > 2.0.CO;2.

Yeh, S.-W., J.-S. Kug, and S.-I. An, 2014: Recent progress on two types of El Niño: Observations, dynamics, and future changes. Asia-Pac. J. Atmos. Sci., 50, 69-81, https://doi.org/10.1007/ s13143-014-0028-3.

Zanchettin, D. S., O. Bothe, H. F. Graf, N.-E. Omrani, A. Rubino, and J. H. Jungclaus, 2016: A decadally delayed response of the tropical Pacific to Atlantic multidecadal variability. Geophys. Res. Lett., 43, 784-792, https://doi.org/ 10.1002/2015GL067284.

Zhang, L., C. Wang, Z. Song, and S.-K. Lee, 2014: Remote effect of the model cold bias in the tropical North Atlantic on the warm bias in the tropical southeastern Pacific. J. Adv. Model. Earth Syst., 6, 1016-1026, https://doi.org/10.1002/2014MS000338.

Zhang, R., and T. L. Delworth, 2005: Simulated tropical response to a substantial weakening of the Atlantic thermohaline circulation. J. Climate, 18, 1853-1860, https://doi.org/10.1175/JCLI3460.1.

- and - 2007: Impact of the Atlantic multidecadal oscillation on North Pacific climate variability. Geophys. Res. Lett., 34, L23708, https://doi.org/10.1029/2007GL031601.

Zhou, W., and J. Chan, 2007: ENSO and the South China Sea summer monsoon onset. Int. J. Climatol., 27, 157-167, https:// doi.org/10.1002/joc. 1380 .

Zuo, J., W. Li, C. Sun, and H.-C. Ren, 2018: Remote forcing of the northern tropical Atlantic SST anomalies on the western North Pacific anomalous anticyclone. Climate Dyn., 52, 28372853, https://doi.org/10.1007/S00382-018-4298-9. 